Defraeye T., Blocken B., Carmeliet J. (2010), CFD analysis of convective heat transfer at the surfaces of a cube immersed in a turbulent boundary layer, International Journal of Heat and Mass Transfer 53 (1-3), 297-308. http://dx.doi.org/10.1016/j.ijheatmasstransfer.2009.09.029

\title{
CFD analysis of convective heat transfer at the surfaces of a cube immersed
} in a turbulent boundary layer

\author{
Thijs Defraeye ${ }^{\mathrm{a}, ~ *}$, Bert Blocken ${ }^{\mathrm{b}}$ and Jan Carmeliet ${ }^{\mathrm{c}, \mathrm{d}}$ \\ a Laboratory of Building Physics, Department of Civil Engineering, Katholieke Universiteit Leuven, Kasteelpark \\ Arenberg 40, 3001 Heverlee, Belgium \\ ${ }^{\mathrm{b}}$ Building Physics and Systems, Eindhoven University of Technology, P.O. Box 513, 5600 Eindhoven, The \\ Netherlands \\ ${ }^{\mathrm{c}}$ Chair of Building Physics, Swiss Federal Institute of Technology ETHZ, Wolfgang-Pauli-Strasse 15, 8093 Zürich, \\ Switzerland \\ ${ }^{\mathrm{d}}$ Laboratory for Building Science and Technologies, Swiss Federal Laboratories for Materials Testing and \\ Research, Empa, Überlandstrasse 129, 8600 Dübendorf, Switzerland
}

\begin{abstract}
Steady RANS (Reynolds-Averaged Navier-Stokes) CFD is used to evaluate the forced convective heat transfer at the surfaces of a cube immersed in a turbulent boundary layer, for applications in atmospheric boundary layer (ABL) wind flow around surface-mounted obstacles such as buildings. Two specific configurations are analysed. First, a cube placed in turbulent channel flow at a Reynolds number of $4.6 \times 10^{3}$ is considered to validate the numerical predictions by comparison with wind-tunnel measurements. The results obtained with low-Reynolds number modelling (LRNM) show a satisfactory agreement with the experimental data for the windward surface. Secondly, a cube exposed to high-Reynolds number ABL flow is considered. The heat transfer in the boundary layer is analysed in detail. The dimensionless parameter $\mathrm{y}^{*}$, which takes into account turbulence, is found to be more appropriate for evaluating heat transfer than the commonly used $\mathrm{y}^{+}$value. Standard wall functions, which are frequently used for high-Reynolds number flows, overestimate the convective heat transfer coefficient (CHTC) significantly $( \pm 50 \%)$ compared to LRNM. The distribution of the CHTC- $\mathrm{U}_{10}$ correlation over the windward surface is reported for Reynolds numbers of $3.5 \times 10^{4}$ to $3.5 \times 10^{6}$ based on the cube height and $U_{10}$, where $U_{10}$ is the wind speed in the undisturbed flow at a height of $10 \mathrm{~m}$.
\end{abstract}

Keywords: convective heat transfer coefficient, CFD, RANS, building, cube, turbulent boundary layer

\section{Nomenclature}

A coefficient in power-law correlation

B exponent in power-law correlation

$\mathrm{c}_{\mathrm{p}} \quad$ specific heat capacity $(\mathrm{J} / \mathrm{kgK})$

\footnotetext{
* Corresponding author. Tel.: +32 (0)16321348; Fax: +32 (0)16321980. E-mail address: thijs.defraeye@bwk.kuleuven.be
} 
Defraeye T., Blocken B., Carmeliet J. (2010), CFD analysis of convective heat transfer at the surfaces of a cube immersed in a turbulent boundary layer, International Journal of Heat and Mass Transfer 53 (1-3), 297-308. http://dx.doi.org/10.1016/j.ijheatmasstransfer.2009.09.029

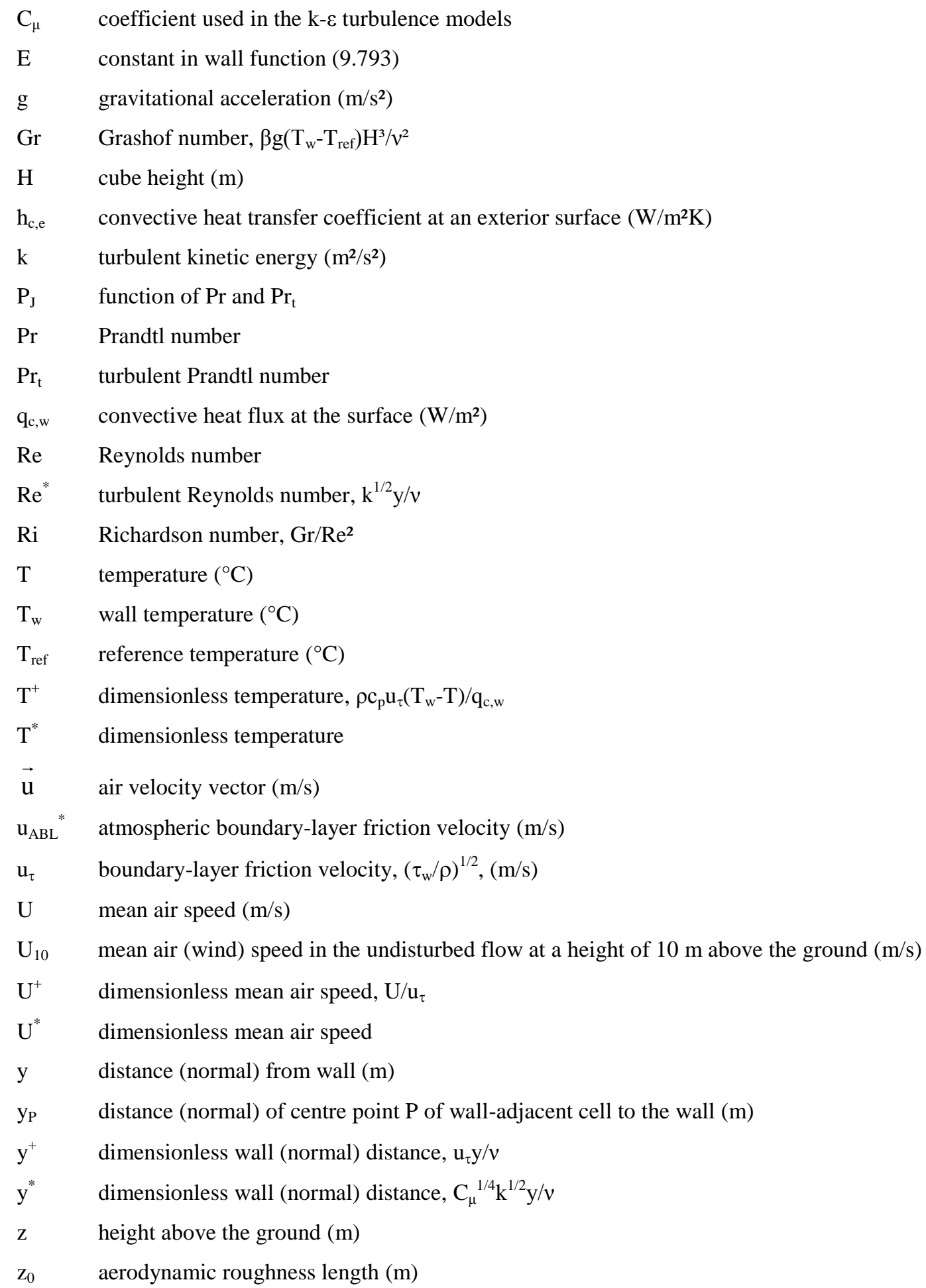

\section{Greek symbols}

$\beta \quad$ thermal volumetric expansion coefficient of air $(1 / \mathrm{K})$

$\delta \quad$ boundary-layer thickness $(\mathrm{m})$

$\varepsilon \quad$ turbulence dissipation rate $\left(\mathrm{m}^{2} / \mathrm{s}^{3}\right)$ 
Defraeye T., Blocken B., Carmeliet J. (2010), CFD analysis of convective heat transfer at the surfaces of a cube immersed in a turbulent boundary layer, International Journal of Heat and Mass Transfer 53 (1-3), 297-308. http://dx.doi.org/10.1016/j.ijheatmasstransfer.2009.09.029

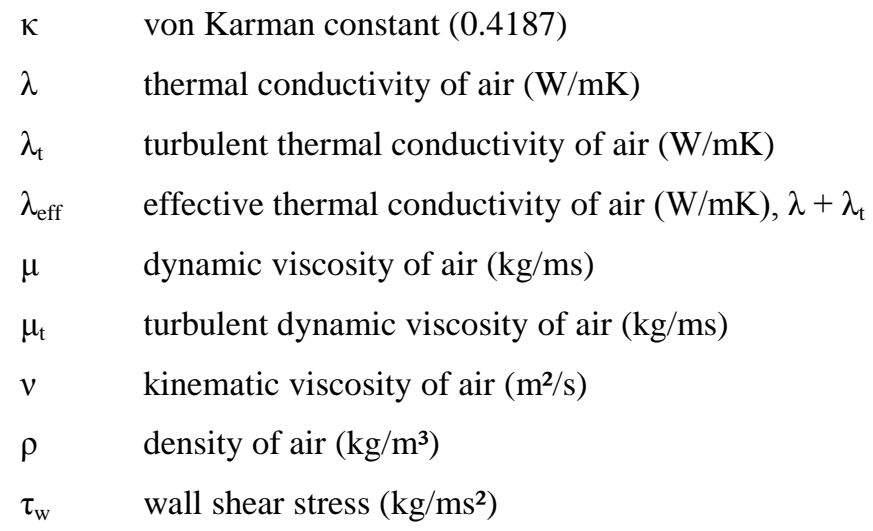

\section{Abbreviations}

$\begin{array}{ll}\text { ABL } & \text { Atmospheric Boundary Layer } \\ \text { CHTC } & \text { Convective Heat Transfer Coefficient } \\ \text { CMTC } & \text { Convective Mass Transfer Coefficient } \\ \text { FVM } & \text { Finite Volume Method } \\ \text { LES } & \text { Large-Eddy Simulation } \\ \text { LRNM } & \text { Low-Reynolds Number Modelling } \\ \text { RANS } & \text { Reynolds-Averaged Navier-Stokes } \\ \text { rk- } \varepsilon & \text { realizable k- } \varepsilon \text { model } \\ \text { SST k- } \omega & \text { Shear Stress Transport k- } \omega \text { model } \\ \text { sk- } \varepsilon & \text { standard k- } \varepsilon \text { model } \\ \text { URANS } & \text { Unsteady Reynolds-Averaged Navier-Stokes } \\ \text { WF } & \text { Wall Functions }\end{array}$

Subscripts

P centre point $\mathrm{P}$ of wall-adjacent cell

\section{Introduction}

The convective heat transfer at surfaces of bluff bodies immersed in turbulent boundary layers at moderate to high Reynolds numbers is of interest in many fields of research. A typical example are buildings where air flow in the atmospheric boundary layer (ABL), namely wind, can have a significant effect on the heat loss at the exterior building surface and the surface temperatures. Usually, the convective heat transfer at an exterior building surface is modelled by convective heat transfer coefficients (CHTCs), which relate the convective heat flux normal to the wall $\left(\mathrm{q}_{\mathrm{c}, \mathrm{w}}\right)$ to the difference between the surface temperature at the wall, $\mathrm{T}_{\mathrm{w}}$, and a reference temperature, $\mathrm{T}_{\text {ref: }}$ : 
Defraeye T., Blocken B., Carmeliet J. (2010), CFD analysis of convective heat transfer at the surfaces of a cube immersed in a turbulent boundary layer, International Journal of Heat and Mass Transfer 53 (1-3), 297-308. http://dx.doi.org/10.1016/j.ijheatmasstransfer.2009.09.029

$h_{c, e}=\frac{q_{c, w}}{\left(T_{w}-T_{r e f}\right)}$

$\mathrm{T}_{\text {ref }}$ is generally taken as the air temperature of the outside environment. The convective heat flux is assumed positive away from the wall. For buildings, the CHTC is relevant for several purposes.

Knowledge of the CHTC is required to assess the energy performance of buildings. It appears in several building design guides and it is used by Building Energy Simulation programs. Apart from buildings, the CHTC is also used to determine the convective heat losses of greenhouses [1], tent-like structures and solar collectors [2-4]. So-called Urban Canopy Models [5-7], which are developed to assess the climate in urban areas, e.g. heat islands, require accurate predictions of the CHTC. These mesoscale models use CHTCs to quantify the turbulent heat fluxes from building surfaces and streets in the urban canopy. The CHTC is also relevant in hygrothermal analysis of buildings. Here, the magnitude of the CHTC affects the surface temperatures, which are required to assess the risk of surface condensation by undercooling during clear cold nights [8-9]. Moreover, the CHTC is sometimes used to estimate the convective mass transfer coefficient (CMTC), based on the heat and mass transfer analogy. This CMTC can have a considerable influence on the drying of facades [10], wetted by surface condensation or winddriven rain [11].

For the forced convective flow regime, the CHTC is usually correlated to the wind speed at a reference location, for example the mean wind speed in the undisturbed flow at a height of $10 \mathrm{~m}$ above the ground, $\mathrm{U}_{10}$, which is the standard arrangement for weather station anemometers. Usually, linear or power-law correlations are reported. These correlations can be derived by wind-tunnel experiments on flat plates [12] or full-scale experiments on buildings [13-17]. Wind-tunnel experiments of convective heat transfer at the surfaces of bluff bodies can also be used [18-21]. Most of these experiments however consider bluff bodies in rather thin boundary layers $(\delta / \mathrm{H}<1)$ and at relatively low Reynolds numbers $\left(\mathrm{Re}=10^{3}-10^{5}\right.$ ) which makes them not directly applicable for atmospheric flow around buildings. Note that many of the existing correlations only consider a single CHTC value for a specific surface and do not take into account the distribution of the correlation over the surface. An increased spatial resolution over the building surfaces would however be valuable for several applications mentioned above.

Another option to obtain CHTCs is to use Computational Fluid Dynamics (CFD). The main advantages of CFD are that, for a specific building or building configuration, high spatial resolution can be obtained and high-Reynolds number flows for atmospheric conditions $\left(\mathrm{Re}=10^{5}-10^{7}\right)$ can be considered. Apart from the flow field, detailed information of the thermal field is available, also in the boundary-layer region, which is valuable for the analysis of the CHTC. In building aerodynamics, steady RANS is frequently used to model air flow, compared to unsteady RANS (URANS) or Large-Eddy Simulations (LES). Due to the high-Reynolds number flow, wall functions (WF) are commonly used instead of low-Reynolds number modelling (LRNM).

In this paper, the convective heat transfer at the surfaces of a wall-mounted cube immersed in a turbulent boundary layer is analysed with steady RANS. The details of the numerical simulation are described in section 2 . Two different configurations are analysed. The first configuration is a cube placed in turbulent channel flow at moderately low Reynolds numbers (section 3). This configuration is used for validation purposes: the accuracy of 
Defraeye T., Blocken B., Carmeliet J. (2010), CFD analysis of convective heat transfer at the surfaces of a cube immersed in a turbulent boundary layer, International Journal of Heat and Mass Transfer 53 (1-3), 297-308. http://dx.doi.org/10.1016/j.ijheatmasstransfer.2009.09.029

the numerical predictions of surface temperatures and CHTCs is evaluated by comparison with wind-tunnel data. The second configuration is a cube placed in an ABL (section 4). Note that actually a very generic case is considered, i.e. a cube immersed in a turbulent boundary layer at high Reynolds numbers, in order for this study to be of use also in other fields of research, besides buildings. The thermal boundary layer is analysed in detail. A comparison is made between different LRNM approaches and standard wall functions. The distribution of the CHTC over the surfaces is reported and the CHTC is correlated with $U_{10}$ for the windward surface. In section 5, the conclusions are given.

\section{Numerical simulation}

\subsection{Turbulence modelling}

The simulations are performed with the CFD package FLUENT 6.3, which uses the control volume method. Steady RANS is used in combination with a turbulence model. Different two-equation turbulence models are

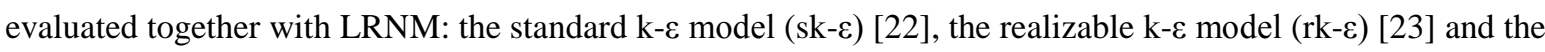
Shear Stress Transport k- $\omega$ model (SST k- $\omega$ ) [24]. The realizable k- $\varepsilon$ model is also evaluated in combination with wall functions.

\subsection{Boundary-layer modelling}

\subsubsection{Wall functions}

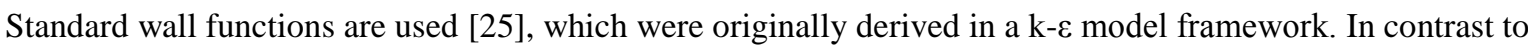
LRNM, the lower part of the boundary layer, namely the viscous sublayer, the buffer layer and a part of the logarithmic layer, is not resolved. Instead the centre point $\mathrm{P}$ of the wall-adjacent cell is placed inside the logarithmic layer and the flow parameters are modelled by wall functions. Typically, $\mathrm{y}^{+}$values of the wall-adjacent cell between 30 and 500 are advised so that it is located in the logarithmic region (e.g. [26]).

These wall functions are usually expressed in dimensionless parameters, namely $\mathrm{y}^{+}, \mathrm{U}^{+}$and $\mathrm{T}^{+}$. In complex flows however, these parameters are not appropriate since the shear stress at the wall $\left(\tau_{\mathrm{w}}\right)$ can become zero, for example in stagnation and reattachment points, by which $\mathrm{y}^{+}$also becomes zero, irrespective of the value of $\mathrm{y}$. In order to avoid this singularity, the following dimensionless parameters can be used: 
Defraeye T., Blocken B., Carmeliet J. (2010), CFD analysis of convective heat transfer at the surfaces of a cube immersed in a turbulent boundary layer, International Journal of Heat and Mass Transfer 53 (1-3), 297-308. http://dx.doi.org/10.1016/j.ijheatmasstransfer.2009.09.029

$$
\begin{aligned}
\mathrm{y}^{*} & =\frac{\rho \mathrm{C}_{\mu}^{1 / 4} \mathrm{k}^{1 / 2} \mathrm{y}}{\mu} \\
\mathrm{U}^{*} & =\frac{\rho \mathrm{C}_{\mu}^{1 / 4} \mathrm{k}^{1 / 2} \mathrm{U}}{\tau_{\mathrm{w}}} \\
\mathrm{T}^{*} & =\frac{\rho \mathrm{C}_{\mu}^{1 / 4} \mathrm{k}^{1 / 2}\left(\mathrm{~T}_{\mathrm{w}}-\mathrm{T}\right) \mathrm{c}_{\mathrm{p}}}{\mathrm{q}_{\mathrm{c}, \mathrm{w}}}
\end{aligned}
$$

These parameters are evaluated at a certain point in the flow field, where $y$ is the normal distance from the wall to that point. The following parameters are also evaluated in this point: turbulent kinetic energy (k), the magnitude of the mean velocity $(\mathrm{U})$, the air density $(\rho)$, the dynamic viscosity of air $(\mu)$, the specific heat capacity of air $\left(c_{p}\right)$ and the temperature $(\mathrm{T}) . \mathrm{C}_{\mu}$ is a coefficient that is equal to 0.09 for the standard k- $\varepsilon$ model. For the realizable k- $\varepsilon$ model, $\mathrm{C}_{\mu}$ is not a constant but is calculated within the model and it is 0.09 in the wall-adjacent cell (in FLUENT 6.3) when wall functions are used. The dimensionless parameters in Eq. (2) are related to k instead of the velocity gradient, which is related to the wall shear stress. They reduce to the generally used dimensionless parameters $\left(\mathrm{y}^{+}, \mathrm{U}^{+}\right.$and $\mathrm{T}^{+}$) for equilibrium boundary layers, which assume a uniform shear stress and heat flux in the near-wall region up to the logarithmic layer. These boundary layers also imply that generation and dissipation of turbulent energy are in balance here. In this case following relation is obtained:

$\sqrt{\frac{\tau_{\mathrm{w}}}{\rho}}=\mathrm{C}_{\mu}^{1 / 4} \mathrm{k}^{1 / 2}$

Functions can be derived for the velocity and temperature profiles in the turbulent region of the boundary layer, based on some assumptions regarding the flow and the distribution of $\mathrm{k}$ and the turbulence dissipation rate $(\varepsilon)$ in the boundary layer (e.g. [27]). Such wall functions are used to determine the flow parameters in the centre point $\mathrm{P}$ of the wall-adjacent cell and are given by Eq. (4):

$$
\begin{array}{ll}
\mathrm{U}_{\mathrm{P}}^{*}=\frac{1}{\kappa} \ln \left(\mathrm{Ey}_{\mathrm{P}}^{*}\right) & \mathrm{y}_{\mathrm{P}}^{*}>\mathrm{y}_{\mathrm{v}}^{*}=11.225 \\
\mathrm{~T}_{\mathrm{P}}^{*}=\operatorname{Pr}_{\mathrm{t}}\left(\frac{1}{\kappa} \ln \left(\mathrm{Ey}_{\mathrm{P}}^{*}\right)+\mathrm{P}_{\mathrm{J}}\right) & \mathrm{y}_{\mathrm{P}}^{*}>\mathrm{y}_{\mathrm{T}}^{*}=11.639
\end{array}
$$

where $\operatorname{Pr}$ and $\operatorname{Pr}_{\mathrm{t}}$ are respectively the molecular (0.74 for air) and turbulent (0.85) Prandtl number, E is a constant (9.793) and $\mathrm{P}_{\mathrm{J}}$ is an empirical function of $\operatorname{Pr}$ and $\operatorname{Pr}_{\mathrm{t}}$ and is equal to -1.12 in this case (air). All the previously mentioned numerical values in Eq. (4) are those used in FLUENT 6.3. The lower limits of $\mathrm{y}^{*}$ for the logarithmic law (Eq. (4)) are also specified, namely $\mathrm{y}_{\mathrm{v}}{ }^{*}$ and $\mathrm{y}_{\mathrm{T}}{ }^{*}$. Below these $\mathrm{y}^{*}$ values, wall functions use the linear law for velocity and temperature: 
Defraeye T., Blocken B., Carmeliet J. (2010), CFD analysis of convective heat transfer at the surfaces of a cube immersed in a turbulent boundary layer, International Journal of Heat and Mass Transfer 53 (1-3), 297-308. http://dx.doi.org/10.1016/j.ijheatmasstransfer.2009.09.029

$$
\begin{array}{ll}
\mathrm{U}^{*}=\mathrm{y}^{*} & \mathrm{y}^{*}<\mathrm{y}_{\mathrm{v}}^{*}=11.225 \\
\mathrm{~T}^{*}=\operatorname{Pr} \mathrm{y}^{*} & \mathrm{y}^{*}<\mathrm{y}_{\mathrm{T}}^{*}=11.639
\end{array}
$$

The combination of the linear and logarithmic laws is called the law-of-the-wall and both curves intersect at $\mathrm{y}_{\mathrm{v}}{ }^{*}$ and

$\mathrm{y}_{\mathrm{T}}{ }^{*}$. For equilibrium boundary layers, these equations reduce to the generally used universal law-of-the-wall, which is defined as a function of $\mathrm{y}^{+}, \mathrm{U}^{+}$and $\mathrm{T}^{+}$. In the present study however, the boundary layers at the cube surface will not be in equilibrium conditions and it will be shown that $\mathrm{y}^{*}$ and $\mathrm{y}^{+}$can differ significantly for wall-function grids. Since the $\mathrm{y}^{*}$ value is used by the wall functions (Eq. (4) and Eq. (5)) and not the $\mathrm{y}^{+}$value, it is the $\mathrm{y}^{*}$ value of the wall-adjacent cell that should have a value of about 30 - 500 in order to be located in the logarithmic layer.

\subsection{2. $L R N M$}

The SST k- $\omega$ model itself can account for low-Reynolds number effects since it was developed for this purpose. It uses a k- $\omega$ model for the near-wall region and blends it with a standard $k-\varepsilon$ model formulation in the turbulent core region of the flow. The $k-\varepsilon$ models themselves were primarily developed for high-Reynolds number flows. Many low-Reynolds number modifications of the k- $\varepsilon$ model consider a two-layer approach. Thereby, the turbulent core region of the flow is resolved with the k- $\varepsilon$ model and a low-Reynolds number model is used to resolve the viscosity-affected region. In FLUENT 6.3, the one-equation Wolfshtein model [28] is used to take care of the viscosity-affected region. For this low-Reynolds number k- $\varepsilon$ model, it is the region where the turbulent Reynolds number $\mathrm{Re}^{*}$ is smaller than 200 , where:

$\operatorname{Re}^{*}=\frac{k^{1 / 2} \mathrm{y}}{v}$

All Reynolds numbers reported in this paper are determined using the air properties defined in Table 1. Using the definition of $\mathrm{y}^{*}$ with $\mathrm{C}_{\mu}=0.09$, the viscosity-affected region is confined to $\mathrm{y}^{*}<110$. LRNM grids typically require a dimensionless wall distance ( $\mathrm{y}^{+}$or $\mathrm{y}^{*}$ ) of the wall-adjacent cell of about 1 (e.g. [26]). Note that at high Reynolds numbers, very fine cells close to the wall are required which is not very practical for grid generation for complex geometries and which is one of the reasons that wall functions are mostly used.

\subsection{Heat transfer modelling}

Following heat transfer equation is solved (FLUENT 6.3) if buoyancy and viscous dissipation of heat are not taken into account and incompressible flow is assumed:

$$
\frac{\partial \rho c_{\mathrm{p}} \mathrm{T}}{\partial \mathrm{t}}+\nabla\left(\rho \mathrm{c}_{\mathrm{p}} \mathrm{Tu}\right)=\nabla\left(\lambda_{\text {eff }} \nabla \mathrm{T}\right)
$$


Defraeye T., Blocken B., Carmeliet J. (2010), CFD analysis of convective heat transfer at the surfaces of a cube immersed in a turbulent boundary layer, International Journal of Heat and Mass Transfer 53 (1-3),

297-308. http://dx.doi.org/10.1016/j.ijheatmasstransfer.2009.09.029

where $\overrightarrow{\mathrm{u}}$ is the mean air velocity vector and $\lambda_{\text {eff }}$ represents the effective thermal conductivity of the air, which is defined as the sum of the thermal conductivity $(\lambda)$ and the turbulent thermal conductivity $\left(\lambda_{t}\right)$ :

$$
\lambda_{\text {eff }}=\lambda+\lambda_{t}=\lambda+\frac{c_{p} \mu_{t}}{\operatorname{Pr}_{t}}
$$

The turbulent thermal conductivity is proportional to the turbulent viscosity $\left(\mu_{\mathrm{t}}\right)$. In the evaluated turbulence models, $\mu_{t}$ in the boundary-layer region is a function of $k^{1 / 2} \mathrm{y}$ [29]. Wall functions (Eq. (4) and Eq. (5)) are also derived under the assumption that $\mu_{\mathrm{t}}$ is proportional to $\mathrm{k}^{1 / 2} \mathrm{y}$ and consequently to $\mathrm{y}^{*}$ [27]. Thereby the turbulent thermal conductivity is linked to $\mathrm{k}$ and not to the velocity gradient which can give a significant improvement in predictions of wall heat transfer [30]. In accordance with experiments, simulations can thus predict a significant amount of heat transfer at stagnation points, where generally low velocities are found together with a relatively high turbulent kinetic energy.

\subsection{Other simulation parameters}

It can be shown that for the validation study (see section 3), the Richardson number is considerably smaller than one and therefore buoyancy effects can be neglected. For the simulations with the atmospheric flow however, buoyancy effects can be important as a result of the rather low wind speeds that are used in the analysis. They will not be taken into account here since in that case the flow field will become dependent on the specific thermal boundary conditions. Thereby, the focus of this paper is only on forced convection. Radiation effects are also not considered in the simulations. For the validation study, the radiative heat flux is about one order of magnitude smaller than the convective flux [19], which limits its influence on the CHTC distribution. Second-order discretisation schemes are used throughout. The SIMPLE algorithm is used for pressure-velocity coupling. Pressure interpolation is second order. Convergence was assessed by monitoring the velocity, $\mathrm{k}$ and temperature on specific locations in the flow field and the heat fluxes on the surfaces of the cube.

\section{Cube in turbulent channel flow: Validation study}

\subsection{Experimental setup}

The experiment of Meinders et al. [20] (see also [19]) is used for validation purposes. In this experiment, the convective heat transfer at the surfaces of a cube placed in turbulent channel flow was evaluated (Fig. 1). The channel had a height of $50 \mathrm{~mm}$ and a depth (out of plane direction in Fig. 1) of $600 \mathrm{~mm}$. The cube had a height $(\mathrm{H})$ of $15 \mathrm{~mm}$. Experiments were performed at several Reynolds numbers, ranging from $2.8 \times 10^{3}$ to $5.1 \times 10^{3}$, based on the cube height and the bulk velocity. For the validation study, a Reynolds number of $4.6 \times 10^{3}$ was considered since 
Defraeye T., Blocken B., Carmeliet J. (2010), CFD analysis of convective heat transfer at the surfaces of a cube immersed in a turbulent boundary layer, International Journal of Heat and Mass Transfer 53 (1-3), 297-308. http://dx.doi.org/10.1016/j.ijheatmasstransfer.2009.09.029

flow field data were also available at this Reynolds number. The corresponding bulk velocity in the channel was $4.47 \mathrm{~m} / \mathrm{s}$. The laminar boundary layer on the lower channel wall was tripped into turbulence by a boundary-layer trip $750 \mathrm{~mm}$ upstream of the cube, which resulted in a turbulent developing boundary layer on the lower wall. Due to the low Reynolds numbers, an almost laminar boundary layer was found on the upper wall of the channel in the experiment. The cube itself had a copper core $\left(12 \times 12 \times 12 \mathrm{~mm}^{3}\right)$ around which an epoxy layer of $1.5 \mathrm{~mm}$ was applied on all surfaces. The copper core was heated at a constant temperature of $75^{\circ} \mathrm{C}$ by a dissipating source (resistance wire) that was placed inside the core. Due to the high thermal conductivity of the copper, a uniformly distributed temperature at the interior of the epoxy layer was obtained. The temperature of the approach flow was $21^{\circ} \mathrm{C}$. The CHTC was determined by measuring the exterior surface temperature of the epoxy layer by infrared thermography. Afterwards, the temperature distribution in the epoxy layer and the resulting heat flux at the exterior surface were calculated by Meinders et al. [20] with a Finite Volume Method (FVM), using the temperature boundary conditions on the interior and exterior surfaces of the cube as input parameters. More information on the experimental setup and the procedure to obtain the temperature and CHTC data can be found in [19]. Here, the author reported an overall experimental uncertainty of the surface temperatures, obtained by infrared thermography, of $0.4^{\circ} \mathrm{C}$ in the mid plane of the cube and $0.6^{\circ} \mathrm{C}$ at the edge zones. The mid plane is a region of $12 \times 12 \mathrm{~mm}^{2}$ in the centre of each surface and the edge zones are defined as the remainder of the surface (see Fig. 1). For the CHTC, experimental uncertainties of $5 \%$ and $10 \%$ were reported for the mid plane and edge zones respectively.

\subsection{Numerical model}

The size of the three-dimensional computational domain (Fig. 2) is determined according to the guidelines by Franke et al. [26], except the height of the domain, which is already prescribed by the channel height.

Experimental data of the approach flow can be used to provide realistic inlet conditions for the numerical simulations. For this validation study, another approach is followed for several reasons: (1) the inlet profiles for mean air speed and streamwise turbulence intensity are only specified for the lower part of the channel flow and no information is available of the lateral and spanwise turbulence intensities; (2) no information on $\varepsilon$ is provided. Therefore, in the present paper, appropriate inlet conditions for the simulations are determined by a twodimensional simulation of an empty, perfectly smooth channel in which a low-turbulent, uniform velocity profile of $4.47 \mathrm{~m} / \mathrm{s}$ is imposed at the inlet. This boundary condition results in a developing turbulent boundary layer at both channel walls. In the experiment, the cube is located at $750 \mathrm{~mm}(50 \mathrm{H})$ downstream of the boundary-layer trip. In the two-dimensional simulation, the velocity profile and turbulence parameters are extracted at $675 \mathrm{~mm}(45 \mathrm{H})$ downstream of the inlet. These profiles are used as inlet conditions for the three-dimensional simulation with the cube (Fig. 3) since the inlet for the three-dimensional simulation is located at 5H $(75 \mathrm{~mm}$ ) upstream of the cube. For the lower part of the channel flow, the resulting mean velocity profile agrees quite well with experimental data and is within the experimental uncertainty (5\%). For the predicted turbulence intensity, larger discrepancies (up to $40 \%$ in the lower part of the boundary layer) are noticed if compared with the streamwise intensity of the experiment. These discrepancies are attributed to the isotropic turbulence prediction by the turbulence model. For 
Defraeye T., Blocken B., Carmeliet J. (2010), CFD analysis of convective heat transfer at the surfaces of a cube immersed in a turbulent boundary layer, International Journal of Heat and Mass Transfer 53 (1-3), 297-308. http://dx.doi.org/10.1016/j.ijheatmasstransfer.2009.09.029

the upper part of the channel flow, the simplification of the inlet boundary conditions will have some effect on the predicted flow field since in reality, a laminar boundary layer was found at the upper wall [20]. Nevertheless, preliminary simulations showed that the resulting CHTCs on the surfaces of the cube are quite insensitive to the boundary-layer profile on the upper wall, except for the top surface of the cube. The temperature of the approach flow is set at $21^{\circ} \mathrm{C}$. This temperature is taken as the reference temperature to calculate the CHTC (Eq. (1)).

For the lateral boundaries specified in Fig. 2, periodic boundary conditions [29] are used. Zero static pressure is imposed at the outlet of the domain.

The top and ground boundaries are modelled as no-slip boundaries. These boundaries are assumed to be perfectly smooth since the surface roughness values cannot be specified if LRNM is used [29]. The upper wall of the channel is assumed to be adiabatic. As can be noticed in Fig. 1b, it is difficult to specify appropriate thermal boundary conditions for the lower wall of the channel in the vicinity of the cube. Therefore, this region is simplified by assuming that the lower channel wall is adiabatic and the copper core extends all the way to the lower wall (Fig. 3). Meinders et al. [20] also had difficulties in modelling this region in order to calculate the temperature distribution inside the epoxy layer with FVM. Therefore, Meinders et al. [20] did not report experimental results for the lower part of the cube, namely the first $1.5 \mathrm{~mm}$ near the lower channel wall. A detailed description of the applied modelling technique can be found in [19].

For the cube, only the epoxy layer is modelled and at its interior surface, a constant temperature of $75^{\circ} \mathrm{C}$ is imposed, according to the experiment. The properties that are used for the epoxy can be found in [19] and are reported in Table 1 . The surfaces of the cube are modelled as perfectly smooth, no-slip boundaries.

An appropriate LRNM grid (Fig. 2) is built according to general RANS practice, based on a grid sensitivity analysis. For the estimation of the discretisation error, the grid convergence index, which is based on Richardson extrapolation, is used, as proposed by Roache [31] and extended by Eça and Hoekstra [32]. A grid refinement factor of $2^{1 / 2}$ is employed. Thereby, the average discretisation error over the cube is about $0.5^{\circ} \mathrm{C}$ for temperature. The cell density in the near-wall region is dependent on the boundary-layer modelling approach that is used. The grid is a hybrid grid (hexahedral and prismatic cells) consisting of about $8 \times 10^{5}$ cells for LRNM. The highest $\mathrm{y}^{+}$values are attained at the edges of the cube, which are smaller than 2. Wall-function modelling is not considered since the required cell size of the wall-adjacent cells in the wall-normal direction would be about one tenth of the cube height, due to the low Reynolds numbers. Such a large cell size would result in a significant loss in resolution of the flow field in the near-wall region.

\subsection{Results and discussion}

In Fig. 4, the temperature distribution in a vertical and horizontal centreplane on the cube surfaces is reported both for experiments and numerical simulations. In Fig. 5, the CHTC at the same locations is reported. The edge zones (see Fig. 1) are marked by the dotted vertical black lines. The results show significant discrepancies between experiments and numerical simulations at some locations on the surfaces of the cube. As mentioned earlier, the differences with the experiments near the lower channel wall can be partially attributed to the simplified boundary 
Defraeye T., Blocken B., Carmeliet J. (2010), CFD analysis of convective heat transfer at the surfaces of a cube immersed in a turbulent boundary layer, International Journal of Heat and Mass Transfer 53 (1-3), 297-308. http://dx.doi.org/10.1016/j.ijheatmasstransfer.2009.09.029

conditions that are used in the numerical model. However, it is remarkable that on almost all surfaces, considerable differences with the experimental data are found for the CHTC at the edges whereas the predicted temperature profiles agree much better in these zones.

The discrepancy for the CHTC could be attributed to the resolution of the infrared thermography measurements, which is limited to about 30x30 points [19], uniformly distributed on each surface. This resolution results in not more than 3 points over an edge region and is rather low in contrast to the numerical simulations. Since these surface temperatures were used to determine the temperature distribution within the epoxy layer [19], which is used to calculate the CHTC, the discrepancy for the CHTC at the edge zones in Fig. 5 could be explained by the low resolution of the experimental surface temperatures in these zones.

At the windward surface, a good quantitative agreement of the surface temperatures is found between experiments and numerical simulations, despite the simplifications made to the numerical model, with respect to the inlet and thermal boundary conditions. All turbulence models produce nearly identical results for the windward surface, which indicates that both LRNM approaches, namely the two-equation SST k- $\omega$ model and the twoequation k- $\varepsilon$ model combined with the one-equation Wolfshtein model, perform well in this region. For the CHTC, a good agreement is also found for the mid plane but, as explained before, not for the edge zones. Again, the differences between the turbulence models are small.

For the leeward surface, the distribution of the predicted surface temperatures agrees quite well with the experimental results, especially for the mid plane, although the temperature is overestimated by the standard and realizable k- $\varepsilon$ models. Only the SST k- $\omega$ model predicts the surface temperatures within the experimental uncertainty for the central part of the surface. The distribution of the predicted CHTC over the leeward surface also agrees quite well with the experimental results for all turbulence models (within $10 \%$ for the central part of the surface) but the standard $k-\varepsilon$ model shows the best agreement with the experiments.

For the top and side surfaces, the experiments show a local minimum of the CHTC (Fig. 5) near the core of the separation vortex and a local maximum at the location where flow reattachment occurs. Meinders et al. [20] attribute the local minimum in the core of the separation vortex to the relatively high air temperature in that zone, which limits heat removal from the surface. The local maximum of the CHTC in the flow reattachment zone is attributed to the low-enthalpy air that impinges on to the surface, which results a relatively high heat transfer rate.

Analysis of the flow field shows that both $\mathrm{k}-\varepsilon$ models however predict a maximum of the CHTC on both surfaces in the region where the core of the separation vortex is predicted in the experiments and simulations. Flow reattachment is found for the $k-\varepsilon$ models on the top surface in the vertical centreplane but not on the side surfaces in the horizontal centreplane. In contrast to the experimental data, an increased CHTC in the reattachment zone is not noticed in the simulations. For the SST k- $\omega$ model, the predicted CHTCs are much lower than the experimental values and no flow reattachment is predicted in the centreplanes of both top and side surfaces. The experimental temperature distribution (Fig. 4) on these surfaces can be explained accordingly, showing a maximum near the core of the separation vortex, as a result of the low heat transfer rate. Again, the predicted surface temperature distribution differs significantly from the experimental data, showing relatively low values in the region where the 
Defraeye T., Blocken B., Carmeliet J. (2010), CFD analysis of convective heat transfer at the surfaces of a cube immersed in a turbulent boundary layer, International Journal of Heat and Mass Transfer 53 (1-3), 297-308. http://dx.doi.org/10.1016/j.ijheatmasstransfer.2009.09.029

core of the separation vortex is predicted for both k- $\varepsilon$ models. The predicted surface temperatures for the SST k- $\omega$ model are much higher than the experimental data.

The discrepancies on the top and side walls are most likely related to the solution of the flow field by the RANS turbulence models, which generally do not perform well in these regions, combined with the fact that flow unsteadiness is not taken into account. In a study of Seeta Ratnam and Vengadesan [33], URANS is used to evaluate the performance of different two-equation turbulence models for the experiment of Meinders et al. [20]. For the standard k- $\varepsilon$ model, no significant improvement of the temperature distribution is noticed compared to the steady RANS results reported in this paper. However by using URANS combined with modified two-equation turbulence models, better agreement with the experimental data is found for the top but especially the side surface.

The use of air properties, such as density, viscosity and thermal conductivity that are temperature dependent (data from Cebeci and Bradshaw [34]) did not improve the results significantly. The predicted CHTCs, calculated with temperature-dependent air properties and calculated with the air properties specified in Table 1, generally differed less than $5 \%$, which is similar to the differences that are found between the predictions of the turbulence models themselves for the windward surface.

Note that the previous simulations are performed at moderately low Reynolds numbers. As a result, the viscosity-affected region, which is the region where the low-Reynolds number models (Wolfshtein and SST k- $\omega$ ) are used, is quite large. Usually, this region is restricted to the vicinity of the wall but in this case, the simulations showed that it stretches out into a significant part of the flow field around the cube, typically to a distance of $10 \%$ $30 \%$ of the cube height. Thereby, the low-Reynolds number models also resolve a significant part of the flow field close to the cube. In the next section, flow at higher Reynolds numbers is considered by which the viscosityaffected region will be much smaller. Since it will be shown here that the CHTC is mainly determined by the heat transfer in the lower part of the boundary-layer region and also that similar CHTC distributions over the surfaces and similar differences between the LRNM approaches are found, it is assumed that the conclusions of this validation study also apply to flow at higher Reynolds numbers. Based on this validation study, it is therefore assumed that the CHTC is predicted with sufficient accuracy on the windward surface of a cube with LRNM and with the used computational parameters, also for higher Reynolds numbers. Note that the accuracy of the CHTC predictions on the other surfaces of the cube can be increased by using other turbulence modelling techniques, like URANS or LES, or by using turbulence model modifications, which was however out of the scope of this study.

\section{Cube in ABL flow}

\subsection{Numerical model}

A cube with a height $\mathrm{H}$ of $10 \mathrm{~m}$ is considered, representing a building in the ABL. The size of the threedimensional computational domain, defined with respect to $\mathrm{H}$, is the same as that of the validation study presented above, except the height of the domain, which is adapted to $6 \mathrm{H}$ [26]. A blockage ratio of $1.5 \%$ is obtained, which is 
Defraeye T., Blocken B., Carmeliet J. (2010), CFD analysis of convective heat transfer at the surfaces of a cube immersed in a turbulent boundary layer, International Journal of Heat and Mass Transfer 53 (1-3), 297-308. http://dx.doi.org/10.1016/j.ijheatmasstransfer.2009.09.029

sufficiently low. At the inlet of the domain, an ABL is imposed. This boundary layer can be described by a vertical profile of the mean horizontal wind speed, the logarithmic law, together with profiles for $\mathrm{k}$ and $\varepsilon$ [35]:

$$
\begin{aligned}
& \mathrm{U}(\mathrm{z})=\frac{\mathrm{u}_{\mathrm{ABL}}^{*}}{\kappa} \ln \left(\frac{\mathrm{z}+\mathrm{z}_{0}}{\mathrm{z}_{0}}\right) \\
& \mathrm{k}=3.3 \mathrm{u}_{\mathrm{ABL}}^{*}{ }^{2} \\
& \varepsilon=\frac{\mathrm{u}_{\mathrm{ABL}}^{*}{ }^{3}}{\kappa\left(\mathrm{z}+\mathrm{z}_{0}\right)}
\end{aligned}
$$

where $\mathrm{u}_{\mathrm{ABL}}{ }^{*}$ is the $\mathrm{ABL}$ friction velocity, $\kappa$ is the von Karman constant $(0.4187), \mathrm{z}$ is the height above the ground and $z_{0}$ is the aerodynamic roughness length. The friction velocity is linked to a reference wind speed. In this paper, $\mathrm{U}_{10}$ is used as the reference wind speed and is taken equal to $0.5 \mathrm{~m} / \mathrm{s}$. Note that other wind speeds are also evaluated in section 4.2.3. In order to retain a dimensionless wall distance $\left(\mathrm{y}^{+}\right)$of the wall-adjacent cell of about 1 , required for LRNM, $y_{P}$ will have to decrease with increasing velocity $\left(\mathrm{U}_{10}\right)$. In order to limit $\mathrm{y}_{\mathrm{P}}$ and thus the required grid resolution in the boundary-layer region for LRNM, rather low wind speeds $\left(\mathrm{U}_{10}\right)$ are used in this study. Even at these wind speeds, the required $y_{P}$ value is very small $\left(0.05 \mathrm{~mm}\right.$ for $\left.U_{10}=5 \mathrm{~m} / \mathrm{s}\right)$ which results in a very fine computational grid in the near-wall region. For the parameter $\mathrm{z}_{0}$, a value of $0.03 \mathrm{~m}$ is chosen, which corresponds to a land surface with low vegetation (e.g. grass) and isolated obstacles [36]. Wind is blowing perpendicular to the windward surface. The temperature of the approach flow is set at $10^{\circ} \mathrm{C}$, which is taken as the reference temperature to calculate the CHTC (Eq. (1)).

The ground boundary is modelled as a no-slip boundary with zero roughness since surface roughness values can not be specified if LRNM is used [29]. This restriction will inevitably introduce streamwise gradients in the vertical profiles of mean horizontal wind speed and turbulence quantities [37]. It is possible to assess the change in the vertical profiles by performing a CFD simulation in an empty computational domain. This simulation is not reported in this paper but showed a distinct change in the profiles in the first meters near the ground surface, which alters the flow field around the cube to some extent. Although wall functions, in contrast to LRNM, can account for surface roughness of the ground boundary in order to avoid these streamwise gradients, no roughness is specified for the wall-function simulations either since a comparison between both simulations methods will be made. The ground boundary is taken adiabatic.

The exterior surfaces of the cube are modelled as no-slip boundaries with zero roughness and have an imposed constant temperature of $20^{\circ} \mathrm{C}$. Note that these boundary conditions are a simplification of the reality since the building envelope itself is not modelled.

For the top boundary, a symmetry boundary condition is used, which assumes that the normal velocity component and the normal gradients at the boundary are zero, resulting in flow parallel to the boundary. Note that other ways to model the top boundary in a more optimised way have been reported by Blocken et al. [37]. This modelling technique however is considered less important in the present case, since a relatively short upstream 
Defraeye T., Blocken B., Carmeliet J. (2010), CFD analysis of convective heat transfer at the surfaces of a cube immersed in a turbulent boundary layer, International Journal of Heat and Mass Transfer 53 (1-3), 297-308. http://dx.doi.org/10.1016/j.ijheatmasstransfer.2009.09.029

region is considered. Zero static pressure is imposed at the outlet. For the lateral boundaries, periodic boundary conditions are used.

An appropriate grid is built for LRNM, based on a grid sensitivity analysis. For the estimation of the discretisation error, the grid convergence index is used (see [32]). Thereby, the average discretisation error over the windward surface is about $5 \%$ for the CHTC. The grid is a hybrid grid (hexahedral and prismatic cells) consisting of about $2.0 \times 10^{6}$ cells for LRNM. Since the $\mathrm{y}^{*}$ values of the wall-adjacent cells are found to be lower (about one order of magnitude) than the $\mathrm{y}^{+}$values for LRNM, the $\mathrm{y}^{+}$value is used to determine the appropriate $\mathrm{y}_{\mathrm{p}}$. The highest $\mathrm{y}^{+}\left(\right.$and $\left.\mathrm{y}^{*}\right)$ values are attained at the edges of the cube and are smaller than 3. For higher wind speeds (see section 4.2.3), a more dense grid is built in the boundary-layer region in order to fulfil the requirement regarding the $\mathrm{y}^{+}$ (and $\mathrm{y}^{*}$ ) value of the wall-adjacent cells.

The wall-function grid has the same cell density as the LRNM grid but only in the near-wall region the grid is adapted in order to provide a higher $\mathrm{y}^{*}$ value for the wall-adjacent cell. This resulted in a grid consisting of about $1.1 \times 10^{6}$ cells with $\mathrm{y}^{*}$ values that vary between about 10 and 280 on the cube surface. On the windward surface, the $\mathrm{y}^{*}$ values are all higher than 30 .

\subsection{Results and discussion}

\subsection{1. $L R N M$}

In this section, the predictions of the CHTC by two LRNM approaches (LRNM rk- $\varepsilon$ model and SST k- $\omega$ model) are compared. The standard k- $\varepsilon$ model is not evaluated for the simulations in this section. Based on the validation study performed earlier, the focus will be mainly on the windward surface in the discussion below.

In Fig. 6, the CHTC distribution over the surfaces is reported in a vertical and horizontal centreplane for both LRNM approaches and for wall functions (rk- $\varepsilon$ model). The results for wall functions are discussed in section 4.2.2. High-Reynolds number flow is considered for this configuration and thereby the viscosity-affected region is much smaller than in the validation study. Nevertheless both LRNM approaches again produce similar results for the windward surface (differences $< \pm 10 \%$ ). The SST k- $\omega$ model predicts higher CHTCs for the leeward surface, analogous to what is found in the validation study. Again a large difference is found on the top and side surfaces.

In Fig. 7, the ratio of the temperature difference $T-T_{\text {ref }}$ to the temperature difference $T_{w}-T_{\text {ref }}$ is presented for different positions at the windward surface along lines normal to the surface, as a function of the $\mathrm{y}^{*}$ value. Here, $\mathrm{T}$ is the air temperature along a certain line, $T_{\text {ref }}$ is the temperature of the approach flow $\left(10^{\circ} \mathrm{C}\right)$ and $\mathrm{T}_{\mathrm{w}}$ is the wall temperature $\left(20^{\circ} \mathrm{C}\right)$. For comparison purposes, the parameter $\mathrm{C}_{\mu}$ is taken constant $(0.09)$ for reporting $\mathrm{y}^{*}$ and $\mathrm{T}^{*}$ data in this paper, although a variable $\mathrm{C}_{\mu}$ is used within the realizable $\mathrm{k}-\varepsilon$ model. The ratio of $\lambda_{t}$ to $\lambda_{\text {eff }}$ is also reported in Fig. 7. Note that this ratio is $50 \%$ if $\lambda_{t}$ is equal to $\lambda$ and is $100 \%$ for $y^{*}$ equal to 0 . In Fig. 7 , y values below 1 are however not reported.

The overall part $( \pm 80 \%)$ of the temperature decrease is found to occur within the viscous sublayer $\left(y^{*}<5\right)$ and the buffer layer $\left(5<y^{*}<30\right)$. Both layers are marked in Fig. 7 by vertical dotted lines. In this region, viscous effects are important, resulting in a region with a low effective conductivity and thus large temperature gradients. 
Defraeye T., Blocken B., Carmeliet J. (2010), CFD analysis of convective heat transfer at the surfaces of a cube immersed in a turbulent boundary layer, International Journal of Heat and Mass Transfer 53 (1-3), 297-308. http://dx.doi.org/10.1016/j.ijheatmasstransfer.2009.09.029

As generally known, the major part of the boundary layer's thermal resistance $( \pm 80 \%)$ is found in this region, which is confirmed by Fig. 7. Here, the boundary layer's resistance is defined as the inverse of the CHTC (Eq. (1)).

For a specific LRNM approach, the temperature and conductivity profiles, as a function of the $\mathrm{y}^{*}$ value, coincide for all positions on the wall. This agreement is due to the fact that $\mu_{\mathrm{t}}$, which determines the turbulent thermal conductivity $\left(\lambda_{\mathrm{t}}\right.$ ), is mainly a function of $\mathrm{k}^{1 / 2} \mathrm{y}$ in the lower part of the boundary-layer region, and thus of $\mathrm{y}^{*}$ (Eq. (2)), for the turbulence models that are considered. Therefore, the $y^{*}$ value is more appropriate to report heat transfer data than the $\mathrm{y}^{+}$value, for which such unique profiles are not found. This remark also applies for the following figures.

If the temperature profiles of both LRNM approaches in Fig. 7 are compared, a good agreement is found (differences $<5 \%$ ). The SST k- $\omega$ model shows a slightly larger gradient in the lower part of the buffer layer for conductivity. The difference between the dimensionless turbulent conductivities is smaller than $10 \%$ (of $\lambda_{\mathfrak{l}} / \lambda_{\text {eff }}$ ) and originates from the different ways of solving for $\mu_{\mathrm{t}}$. Note that $\lambda_{\mathrm{t}}$ can differ significantly for both LRNM approaches at high $\mathrm{y}^{*}$ values, which can however not be noticed from Fig. 7 since $\lambda_{\mathrm{t}} \lambda_{\text {eff }}$ is reported.

In Fig. 8, the dimensionless temperature profiles (Eq. (2)) are compared for different positions at the windward surface along lines normal to the surface, as a function of the $\mathrm{y}^{*}$ value. The parameters which vary along a certain line are k, T and y. The law-of-the-wall for temperature (Eq. (4) and Eq. (5)), which is used by standard wall functions, is also shown. Comparison with this law is however not justified since the equilibrium conditions, as defined in section 2.2.1, are not satisfied for flow at the windward surface.

Both LRNM approaches predict a linear law up to $\mathrm{y}^{*}$ values of about 5. For the realizable $\mathrm{k}-\varepsilon$ model, a large buffer region is found, which extends to $y^{*}$ values of about 100 after which a logarithmic-like law is predicted. This change takes place in the zone where the Wolfshtein and k- $\varepsilon$ model are blended, namely at $\mathrm{y}^{*}$ values of about 110 . For the SST $k-\omega$ model, the buffer region extends to $\mathrm{y}^{*}$ values of about 20.

For a specific LRNM approach, the dimensionless temperature profiles (Fig. 8) along these lines seem to agree well, even up to high $\mathrm{y}^{*}$ values. This good agreement shows that, based on Eq. (2) and the agreement of the temperature profiles (Fig. 7), $\mathrm{q}_{\mathrm{c}, \mathrm{w}}$ is closely related to $\mathrm{k}^{1 / 2}$ in the boundary-layer region. The $\mathrm{k}^{1 / 2} / \mathrm{q}_{\mathrm{c}, \mathrm{w}}$ profiles, as a function of $\mathrm{y}^{*}$, are shown in Fig. 9 for the windward surface. As expected, these profiles agree well for a specific LRNM approach over the whole boundary-layer region.

From Fig. 9, it is also clear that the significant differences between both LRNM approaches in Fig. 8, particularly in the logarithmic region, are actually related to a different prediction of $\mathrm{k}$ since they both predicted a similar $\mathrm{q}_{\mathrm{c}, \mathrm{w}}$ at the windward surface (Fig. 6). Consequently, $\mu_{\mathrm{t}}$ and $\lambda_{\mathrm{t}}$ also differ significantly in this region. This difference (LRNM rk- $\varepsilon$ model and SST k- $\omega$ ) however does not affect the prediction of the heat flux at the wall significantly (differences $<10 \%$ ), which again confirms that convective heat transfer is mainly dependent on the flow and heat transfer (modelling) in the viscous sublayer and the buffer layer, due to the low thermal conductivity of these layers.

\subsubsection{LRNM vs. wall functions}


Defraeye T., Blocken B., Carmeliet J. (2010), CFD analysis of convective heat transfer at the surfaces of a cube immersed in a turbulent boundary layer, International Journal of Heat and Mass Transfer 53 (1-3),

297-308. http://dx.doi.org/10.1016/j.ijheatmasstransfer.2009.09.029

In this section, the predictions of the CHTC by LRNM and wall functions (with rk- $\varepsilon$ model) are compared. In Fig. 6, the CHTC distribution over the surfaces is reported in a vertical and horizontal centreplane. Wall functions and LRNM (rk- $\varepsilon$ model) produce quantitative large differences, although a clear similarity in the distribution over all surfaces can be found. Although the use of wall functions can lead to inaccurate predictions of the flow parameters in the boundary-layer region, its influence on the prediction of the overall flow field around the cube is found to be quite limited for the present study, which explains the qualitative similarity in the CHTC distribution.

The quantitative difference stresses that for heat transfer simulations accurate modelling in the wall-adjacent cells is critical.

In Fig. 10, the dimensionless temperature profiles of wall functions and LRNM (rk- $\varepsilon$ model) are compared for different positions at the windward surface along lines normal to the surface, as a function of $\mathrm{y}^{*}$. For wall functions, the dimensionless temperature $\left(\mathrm{T}^{*}\right)$ of the wall-adjacent cell is forced by the logarithmic law for temperature (Eq. (4)) to a value that is systematically too low. This T* value is used to calculate the heat flux at the wall (Eq. (2)). In the wall-adjacent cell, $\mathrm{k}$ and the temperature however are found to agree quite well (differences $<15 \%$ and $5 \%$ respectively) with those predicted by LRNM (rk- $\varepsilon$ model) at the same location. According to Eq. (2), the much lower $\mathrm{T}^{*}$ value, predicted by wall functions, will thereby mainly result in a heat flux which differs significantly from the LRNM results (differences of about $50 \%$ ). This difference results in the significant overestimation of the CHTC in Fig. 6. Note that wall functions are however still frequently used in high-Reynolds number flows, such as in building aerodynamics.

In Fig. 6, the $\mathrm{y}^{+}$and $\mathrm{y}^{*}$ values for wall functions are also reported in a vertical and horizontal centreplane along lines through the wall-adjacent cell centres. The distance of the wall-adjacent cell to the wall $\left(\mathrm{y}_{\mathrm{P}}\right)$ is constant for a specific surface by which the variation of the $\mathrm{y}^{+}$and $\mathrm{y}^{*}$ values along the surface is only a result of respectively varying wall shear stress $\left(\tau_{\mathrm{w}}\right)$ and $\mathrm{k}$.

The $\mathrm{y}^{+}$value differs significantly from the $\mathrm{y}^{*}$ value in distribution and magnitude which is a result of the different definitions of $\mathrm{y}^{+}$and $\mathrm{y}^{*}$. The magnitude of the $\mathrm{y}^{+}$and $\mathrm{y}^{*}$ values is found to differ more than $100 \%$ at most locations at the windward surface. It is therefore recommended that a wall-function grid is evaluated based on the $\mathrm{y}^{*}$ value and not on the $\mathrm{y}^{+}$value since it is the $\mathrm{y}^{*}$ value that is used by wall functions. In this study, an evaluation based on the $\mathrm{y}^{+}$value would result in a grid size of the wall-adjacent cells $\left(\mathrm{y}_{\mathrm{P}}\right)$ which is larger than the grid size that is currently used. The use of $\mathrm{y}^{+}$does however not necessarily have to lead to less accurate results but can sometimes be in conflict with the wall functions, based on $y^{*}$, which require the $y^{*}$ value to lie within the interval of $30-500$.

The distribution of the CHTC over the different surfaces is quite similar to that of $\mathrm{y}^{*}$, but not to that of $\mathrm{y}^{+}$, which is a result of the fact that, in the turbulence models, heat transfer is not related to velocity gradients but to turbulent fluctuations. This is most clear in the stagnation point on the windward surface, where the shear stress at the wall falls to zero, and therefore also the $\mathrm{y}^{+}$value. Despite the very low velocities that are found in this region, the heat transfer is still significant due to turbulence: the stagnation point can not be distinguished in the CHTC distribution, which is similar to the $\mathrm{y}^{*}$ distribution, since both are related to $\mathrm{k}^{1 / 2}$. The analogy between momentum and heat transfer, which can be found for flat plates, is clearly not valid for this case. 
Defraeye T., Blocken B., Carmeliet J. (2010), CFD analysis of convective heat transfer at the surfaces of a cube immersed in a turbulent boundary layer, International Journal of Heat and Mass Transfer 53 (1-3), 297-308. http://dx.doi.org/10.1016/j.ijheatmasstransfer.2009.09.029

\subsection{3. $C H T C-U_{10}$ correlation}

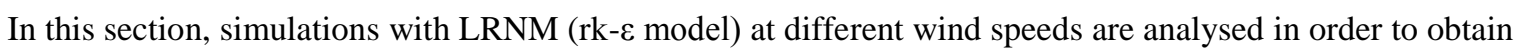
correlations, for the forced convective flow regime and for the windward surface, of the CHTC with the mean wind speed, $\mathrm{U}_{10}$, which is in general available from measurements at a meteorological station. The chosen wind speeds $\mathrm{U}_{10}$ are $0.05,0.5,2.5$ and $5 \mathrm{~m} / \mathrm{s}$ respectively. These wind speeds result in Reynolds numbers, based on the cube height and $\mathrm{U}_{10}$, of about $3.5 \times 10^{4}$ to $3.5 \times 10^{6}$. The use of relatively low wind speeds to obtain correlations for the forced convective flow regime is justified by not taking into account buoyancy in the simulations. The use of these correlations is therefore only justified if the Richardson number is sufficiently low (forced convection) since otherwise the influence of buoyancy on the flow field will have to be taken into account.

A major advantage of the use of CFD in the evaluation of CHTCs is that high spatial resolution data are provided, which allow determining the $\mathrm{CHTC}-\mathrm{U}_{10}$ correlation at every location on a surface. In this case, a powerlaw correlation between the $\mathrm{CHTC}$ and $\mathrm{U}_{10}$ provides the best approximation of the data and can be represented by following equation:

$\mathrm{h}_{\mathrm{c}, \mathrm{e}}=\mathrm{AU}_{10}^{\mathrm{B}}$

where A and B are respectively a coefficient and the exponent, which are location-dependent. The values of this coefficient and exponent are represented in Fig. 11 for the windward surface. The exponent B does not seem to vary a lot over this surface with exception of the zone near the ground surface. The coefficient A increases from the bottom to the top of the windward surface. The correlation of the surface-averaged CHTC with $\mathrm{U}_{10}$ for the windward surface is given by:

$\mathrm{h}_{\mathrm{c}, \mathrm{e}}=5.14 \mathrm{U}_{10}^{0.82}$

The exponent is similar to the value which has been found for turbulent flow over flat plates, namely 0.8 . An agreement can also be found with previous full-scale experiments (i.e. [38]) and numerical simulations (i.e. [39]), for which in both cases an exponent of 0.89 is found. Note however that, in general, a large variability exists within exponents obtained in the past. For example for wind-tunnel experiments on bluff bodies in thin boundary layers ([18-21]), lower exponents have been found, varying from about 0.5 to 0.65 . If a specific correlation, such as Eq. (11), is used, it is important that the specific conditions under which it is derived are acknowledged since the CHTC is dependent on factors such as the building surroundings, building geometry, position on the surface, surface roughness and wind direction. Note that the correlations derived in this paper are determined for an isolated cubic body immersed in a turbulent boundary layer at high Reynolds and low Richardson numbers for flow perpendicular to the windward surface. Since this is a very generic case, the applicability of the correlations is not only limited to buildings. Moreover, similar correlations for other bluff bodies or more complex configurations can be determined in the same way, namely using CFD, as an alternative to wind-tunnel or full-scale experiments. 
Defraeye T., Blocken B., Carmeliet J. (2010), CFD analysis of convective heat transfer at the surfaces of a cube immersed in a turbulent boundary layer, International Journal of Heat and Mass Transfer 53 (1-3), 297-308. http://dx.doi.org/10.1016/j.ijheatmasstransfer.2009.09.029

\section{Conclusions}

In the present study, convective heat transfer at the surfaces of a wall-mounted cube immersed in a turbulent boundary layer was investigated with steady RANS for applications in atmospheric flow around buildings. Two different configurations have been analysed. The first configuration was a cube placed in turbulent channel flow at moderately low Reynolds numbers. Experimental data of the convective heat transfer at the surfaces of the cube were used to validate the accuracy of the numerical simulations. Simulations with both LRNM approaches (LRNM rk- $\varepsilon$ model and SST k- $\omega$ model) showed a good agreement with the experimental data for the windward surface and to a lesser extent for the leeward surface. For the top and side surfaces, considerable discrepancies were found, which were attributed to steady RANS and turbulence model limitations.

The second configuration was a cube, placed in a high-Reynolds number ABL. The focus was on the windward surface for which it was shown that:

1. A precise quantification of the boundary layer's thermal resistance was possible. In this case about $80 \%$ of the thermal resistance was located in the zone with $\mathrm{y}^{*}<30$, as a result of the low thermal conductivity in this region.

2. The $y^{*}$ value was a more appropriate parameter, as opposed to the $y^{+}$value, to report heat transfer characteristics, such as temperature and dimensionless temperature $\left(\mathrm{T}^{*}\right)$, in the boundary-layer region. The reason for this was that, in the turbulence models that were used, the turbulent thermal conductivity $\left(\lambda_{t}\right)$ and the heat flux $\left(\mathrm{q}_{\mathrm{c}, \mathrm{w}}\right)$ but also $\mathrm{y}^{*}$ were related to the turbulent fluctuations $\left(\mathrm{k}^{1 / 2}\right)$.

3. The comparison between two different LRNM approaches (LRNM rk- $\varepsilon$ model and SST k- $\omega$ model) showed a good agreement for the CHTC of the windward surface. The T"-y" profiles however differed significantly in the logarithmic region, due to a different prediction of $\mathrm{k}$ for each LRNM approach. The difference in this region was not manifested in the CHTC predictions.

4. Compared to LRNM, wall functions, which are frequently used for high-Reynolds number flows, predicted a qualitatively similar CHTC distribution but a systematically higher CHTC $( \pm 50 \%)$. Note however that LRNM required a very fine grid in the boundary-layer region at these Reynolds numbers $\left(\mathrm{y}_{\mathrm{P}}\right.$ $\approx 0.05 \mathrm{~mm}$ in this study) which is not very practical for grid generation for complex geometries.

5. The use of the $y^{*}$ value is recommendable for the evaluation of wall-function grids instead of the $y^{+}$value. The $\mathrm{y}^{+}$and $\mathrm{y}^{*}$ values for wall functions differed significantly, generally more than $100 \%$.

6. The CHTC varied significantly over the windward surface of the cube. The distribution of the power-law CHTC- $\mathrm{U}_{10}$ correlation over the windward surface was obtained and was characterised by a quasi-constant exponent B (Eq. (10)) and a coefficient A which increased from the bottom to the top of the surface. A significant advantage, compared to existing correlations, is that the distribution of the correlations over the surfaces is accounted for. Numerical models that rely on these correlations, such as Building Energy Simulation models or Urban Canopy Models, can benefit from this increased spatial resolution. 
Defraeye T., Blocken B., Carmeliet J. (2010), CFD analysis of convective heat transfer at the surfaces of a cube immersed in a turbulent boundary layer, International Journal of Heat and Mass Transfer 53 (1-3), 297-308. http://dx.doi.org/10.1016/j.ijheatmasstransfer.2009.09.029

\section{Acknowledgements}

This research is funded by the Government of Flanders. As a Flemish government institution, IWT-Flanders (Institute for the Promotion of Innovation by Science and Technology in Flanders) supports and stimulates industrial research and technology transfer in the Flemish industry. Their contribution is gratefully acknowledged. 
Defraeye T., Blocken B., Carmeliet J. (2010), CFD analysis of convective heat transfer at the surfaces of a cube immersed in a turbulent boundary layer, International Journal of Heat and Mass Transfer 53 (1-3), 297-308. http://dx.doi.org/10.1016/j.ijheatmasstransfer.2009.09.029

\section{References}

[1] J.C. Roy, T. Boulard, C. Kittas, S. Wang, PA - Precision Agriculture: Convective and ventilation transfers in greenhouses, Part 1: The greenhouse considered as a perfectly stirred tank, Biosystems Engineering 83 (1) (2002) 1-20.

[2] S. Shakerin, Wind-related heat transfer coefficient for flat-plate solar collectors, Transactions of the ASME: Journal of Solar Energy Engineering 109 (1987) 108-110.

[3] S. Sharples, P.S. Charlesworth, Full-scale measurements of wind-induced convective heat transfer from a roof-mounted flat plate solar collector, Solar Energy 62 (2) (1998) 69-77.

[4] J.A. Palyvos, A survey of wind convection coefficient correlations for building envelope energy systems' modelling, Applied Thermal Engineering 28 (8-9) (2008) 801-808.

[5] V. Masson, A physically-based scheme for the urban energy budget in atmospheric models, Boundary-Layer Meteorology 94 (3) (2000) 357-397.

[6] H. Kusaka, H. Kondo, Y. Kikegawa, F. Kimura, A simple single-layer urban canopy model for atmospheric models: Comparison with multi-layer and slab models, Boundary-Layer Meteorology 101 (3) (2001) 329358.

[7] H. Kondo, Y. Genchi, Y. Kikegawa, Y. Ohashi, H. Yoshikado, H. Komiyama, Development of a multi-layer urban canopy model for the analysis of energy consumption in a big city: structure of the urban canopy model and its basic performance, Boundary-Layer Meteorology 116 (3) (2005) 395-421.

[8] D. Camuffo, R. Giorio, Quantitative evaluation of water deposited by dew on monuments, Boundary-Layer Meteorology 107 (3) (2003) 655-672.

[9] D. Aelenei, F.M.A. Henriques, Analysis of the condensation risk on exterior surface of building envelopes, Energy and Buildings 40 (10) (2008) 1866-1871.

[10] H. Janssen, B. Blocken, S. Roels, J. Carmeliet, Wind-driven rain as a boundary condition for HAM simulations: analysis of simplified modelling approaches, Building and Environment 42 (4) (2007) 15551567.

[11] B. Blocken, J. Carmeliet, A review of wind-driven rain research in building science, Journal of Wind Engineering and Industrial Aerodynamics 92 (13) (2004) 1079-1130.

[12] W. Jürges, Der Wärmeübergang an einer ebenen Wand, Beihefte zum Gesundheits-Ingenieur 1 (19) (1924).

[13] N. Ito, K. Kimura, J. Oka, A field experiment study on the convective heat transfer coefficient on exterior surface of a building, ASHRAE Transactions 78 (1) (1972) 184-191.

[14] S. Sharples, Full-scale measurements of convective energy losses from exterior building surfaces, Building and Environment 19 (1) (1984) 31-39.

[15] D.L. Loveday, A.H. Taki, Convective heat transfer coefficients at a plane surface on a full-scale building facade, International Journal of Heat and Mass Transfer 39 (8) (1996) 1729-1742.

[16] A. Hagishima, J. Tanimoto, Field measurements for estimating the convective heat transfer coefficient at building surfaces, Building and Environment 38 (7) (2003) 873-881. 
Defraeye T., Blocken B., Carmeliet J. (2010), CFD analysis of convective heat transfer at the surfaces of a cube immersed in a turbulent boundary layer, International Journal of Heat and Mass Transfer 53 (1-3), 297-308. http://dx.doi.org/10.1016/j.ijheatmasstransfer.2009.09.029

[17] Y. Liu, D.J. Harris, Full-scale measurements of convective coefficient on external surface of a low-rise building in sheltered conditions, Building and Environment 42 (7) (2007) 2718-2736.

[18] M.K. Chyu, V. Natarajan, Local heat/mass transfer distributions on the surface of a wall-mounted cube, Transactions of the ASME: Journal of Heat Transfer 113 (4) (1991) 851-857.

[19] E.R. Meinders, Experimental study of heat transfer in turbulent flows over wall-mounted cubes, $\mathrm{PhD}$ thesis, Technische Universiteit Delft, Delft, The Netherlands, 1998.

[20] E.R. Meinders, K. Hanjalic, R.J. Martinuzzi, Experimental study of the local convection heat transfer from a wall-mounted cube in turbulent channel flow, Transactions of the ASME: Journal of Heat Transfer 121 (3) (1999) 564-573.

[21] H. Nakamura, T. Igarashi, T. Tsutsui, Local heat transfer around a wall-mounted cube in the turbulent boundary layer, International Journal of Heat and Mass Transfer 44 (18) (2001) 3385-3395.

[22] B.E. Launder, D.B. Spalding, Lectures in Mathematical Models of Turbulence, Academic Press, London, England, 1972.

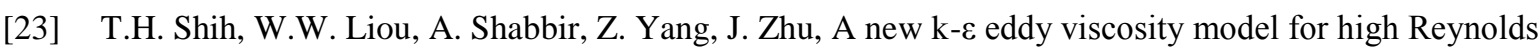
number turbulent flows, Computers \& Fluids 24 (3) (1995) 227-238.

[24] F.R. Menter, Two-equation eddy-viscosity turbulence models for engineering applications, AIAA Journal 32 (8) (1994) 1598-1605.

[25] B.E. Launder, D.B. Spalding, The numerical computation of turbulent flows, Computer Methods in Applied Mechanics and Engineering 3 (2) (1974) 269-289.

[26] J. Franke, A. Hellsten, H. Schlünzen, B. Carissimo, Best practice guideline for the CFD simulation of flows in the urban environment, COST Action 732: Quality assurance and improvement of microscale meteorological models, Hamburg, 2007.

[27] B.E. Launder, On the computation of convective heat transfer in complex turbulent flows, Transactions of the ASME: Journal of Heat Transfer 110 (1988) 1112-1128.

[28] M. Wolfshtein, The velocity and temperature distribution in one-dimensional flow with turbulence augmentation and pressure gradient, International Journal of Heat and Mass Transfer, 12 (1969) 301-318.

[29] Fluent Inc., Fluent 6.3 User’s Guide, Lebanon - New Hampshire, 2006.

[30] M. Casey, T. Wintergerste, ERCOFTAC Special Interest Group on "Quality and Trust in Industrial CFD": Best Practice Guidelines, ERCOFTAC, 2000.

[31] P.J. Roache, Perspective: a method for uniform reporting of grid refinement studies, Journal of Fluids Engineering 116 (3) (1994) 405-413.

[32] L. Eça, M. Hoekstra, A verification exercise for two 2-D steady incompressible turbulent flows, in: P. Neittaanmäki, T. Rossi, M. Majava, O. Pironneau (Eds.), Proceedings of the ECCOMAS 2004, Jyväskylä, Finland, 2004.

[33] G. Seeta Ratnam, S. Vengadesan, Performance of two equation turbulence models for prediction of flow and heat transfer over a wall mounted cube, International Journal of Heat and Mass Transfer 51 (2008) 28342846. 
Defraeye T., Blocken B., Carmeliet J. (2010), CFD analysis of convective heat transfer at the surfaces of a cube immersed in a turbulent boundary layer, International Journal of Heat and Mass Transfer 53 (1-3), 297-308. http://dx.doi.org/10.1016/j.ijheatmasstransfer.2009.09.029

[34] T. Cebeci, P. Bradshaw, Physical and Computational aspects of Convective Heat Transfer, first ed., Springer-Verlag, New York, 1984

[35] P.J. Richards, R.P. Hoxey, Appropriate boundary conditions for computational wind engineering models using the k- $\varepsilon$ turbulence model, Journal of Wind Engineering and Industrial Aerodynamics 46-47 (1993) 145-153.

[36] J. Wieringa, Updating the Davenport roughness classification, Journal of Wind Engineering and Industrial Aerodynamics 41-44 (1992) 357-368.

[37] B. Blocken, T. Stathopoulos, J. Carmeliet, CFD simulation of the atmospheric boundary layer: wall function problems, Atmospheric Environment 41 (2) (2007) 238-252.

[38] M. Yazdanian, J. H. Klems, Measurement of the exterior convective film coefficient for windows in low-rise buildings, ASHRAE Transactions 100 (1) (1994) 1087-1096.

[39] B. Blocken, T. Defraeye, D. Derome, J. Carmeliet, High-resolution CFD simulations for forced convective heat transfer coefficients at the facade of a low-rise building, Building and Environment 44 (12) (2009) 2396-2412. 
Defraeye T., Blocken B., Carmeliet J. (2010), CFD analysis of convective heat transfer at the surfaces of a cube immersed in a turbulent boundary layer, International Journal of Heat and Mass Transfer 53 (1-3), 297-308. http://dx.doi.org/10.1016/j.ijheatmasstransfer.2009.09.029

\section{Figures}

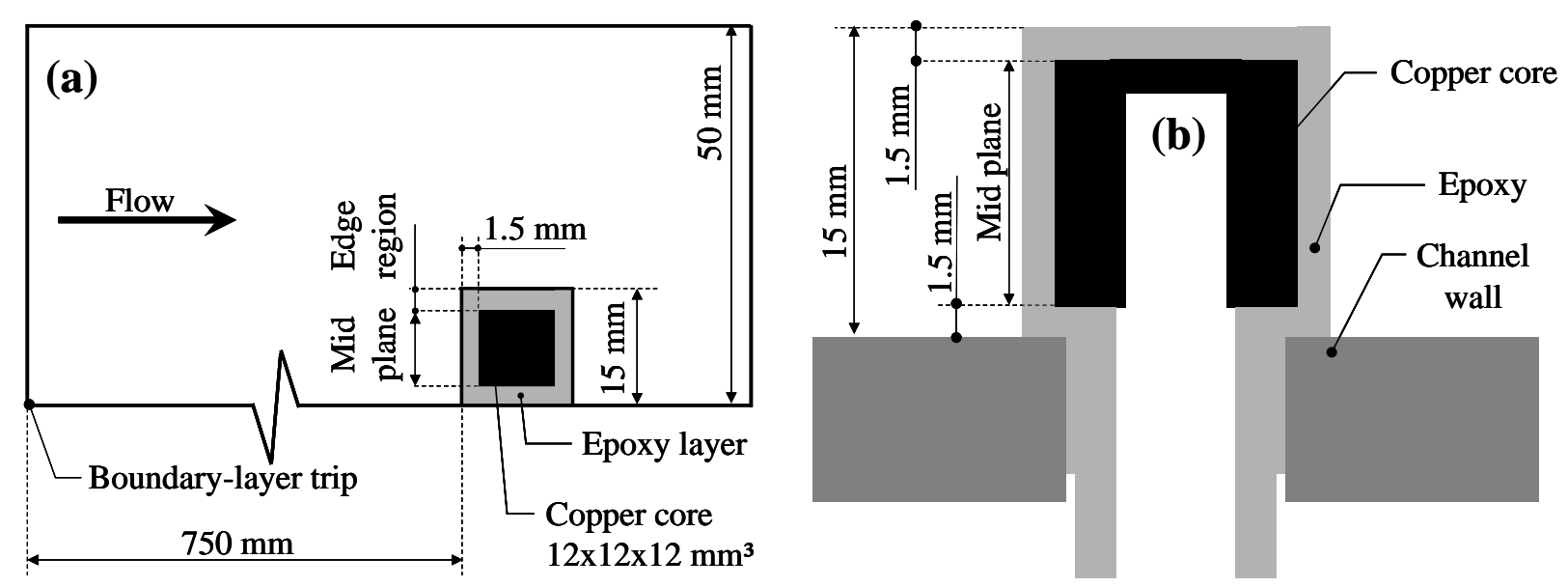

Fig. 1. Experimental setup of Meinders et al. [20] of a heated cube in turbulent channel flow: (a) general setup, (b) detail of cube. 
Defraeye T., Blocken B., Carmeliet J. (2010), CFD analysis of convective heat transfer at the surfaces of a cube immersed in a turbulent boundary layer, International Journal of Heat and Mass Transfer 53 (1-3), 297-308. http://dx.doi.org/10.1016/j.ijheatmasstransfer.2009.09.029

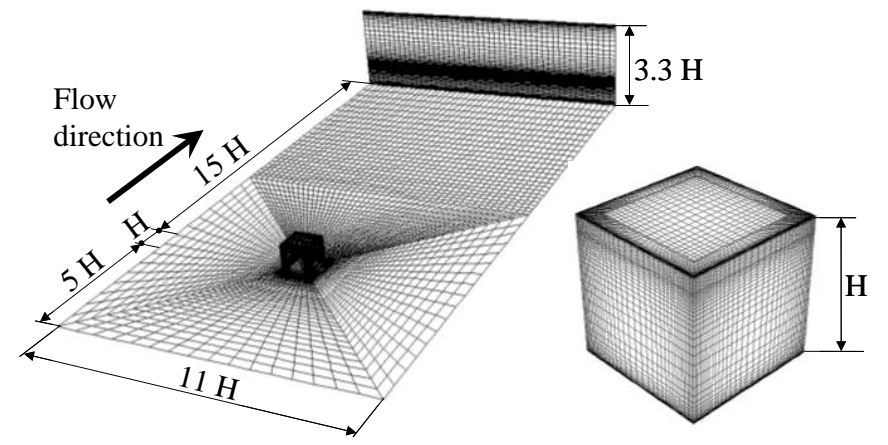

Fig. 2. Computational domain and grid $(\mathrm{H}=15 \mathrm{~mm})$. 
Defraeye T., Blocken B., Carmeliet J. (2010), CFD analysis of convective heat transfer at the surfaces of a cube immersed in a turbulent boundary layer, International Journal of Heat and Mass Transfer 53 (1-3), 297-308. http://dx.doi.org/10.1016/j.ijheatmasstransfer.2009.09.029

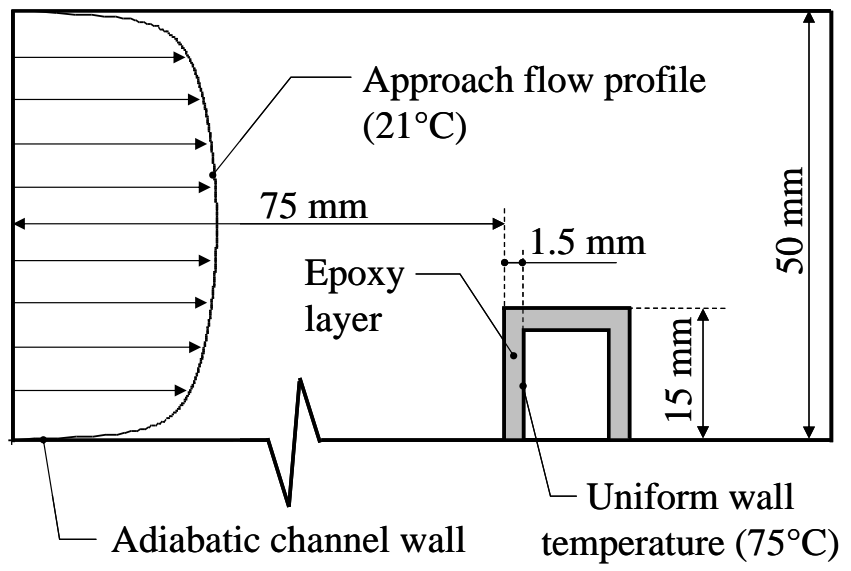

Fig. 3. Model for numerical analysis with thermal boundary conditions. 
Defraeye T., Blocken B., Carmeliet J. (2010), CFD analysis of convective heat transfer at the surfaces of a cube immersed in a turbulent boundary layer, International Journal of Heat and Mass Transfer 53 (1-3),

297-308. http://dx.doi.org/10.1016/j.ijheatmasstransfer.2009.09.029
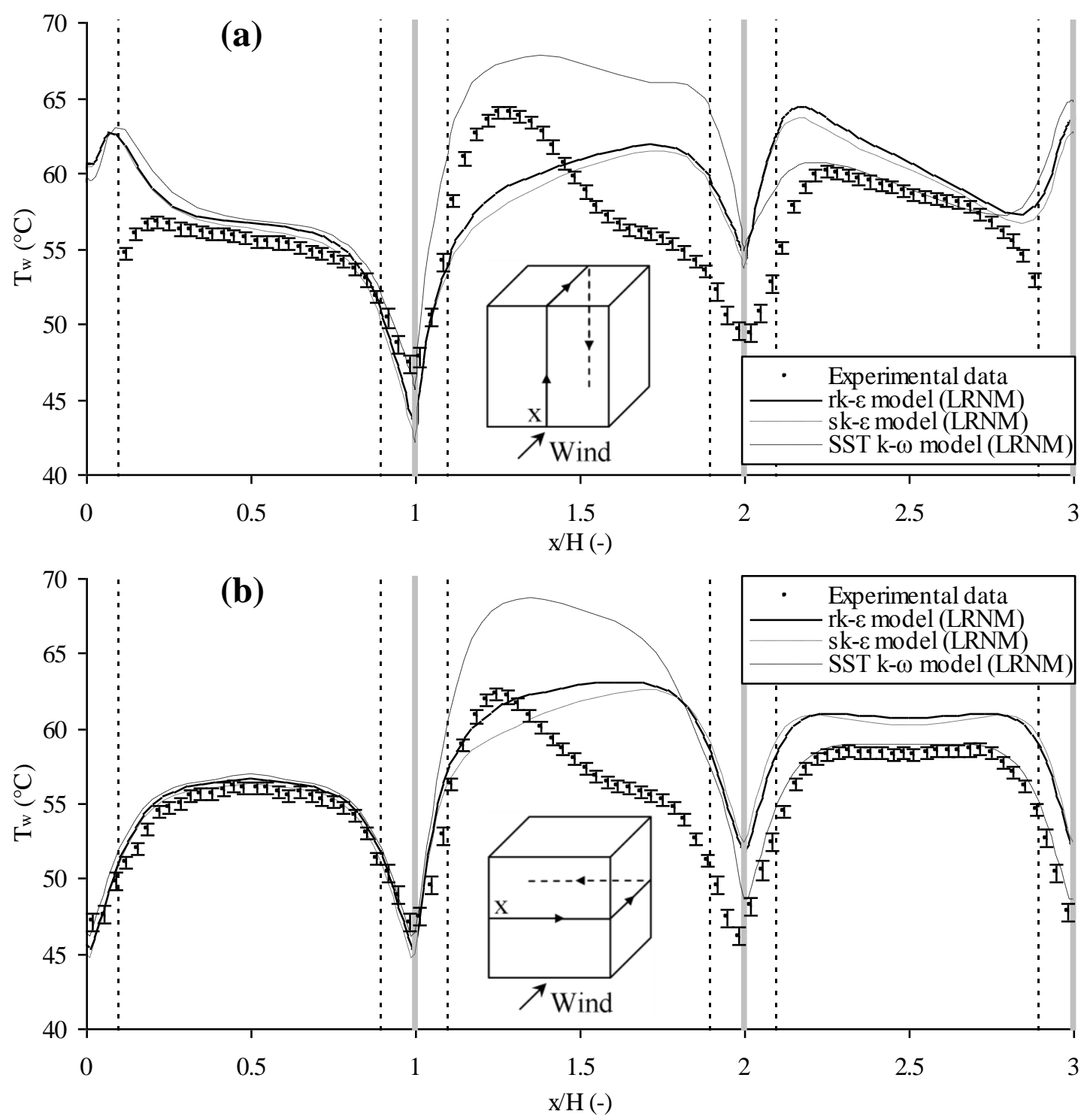

Fig. 4. Temperature distribution on the surfaces of the cube in a vertical (a) and horizontal (b) centreplane comparison of different turbulence models (LRNM) with experimental data (with standard deviation) of Meinders et al. [20]. 
Defraeye T., Blocken B., Carmeliet J. (2010), CFD analysis of convective heat transfer at the surfaces of a cube immersed in a turbulent boundary layer, International Journal of Heat and Mass Transfer 53 (1-3), 297-308. http://dx.doi.org/10.1016/j.ijheatmasstransfer.2009.09.029
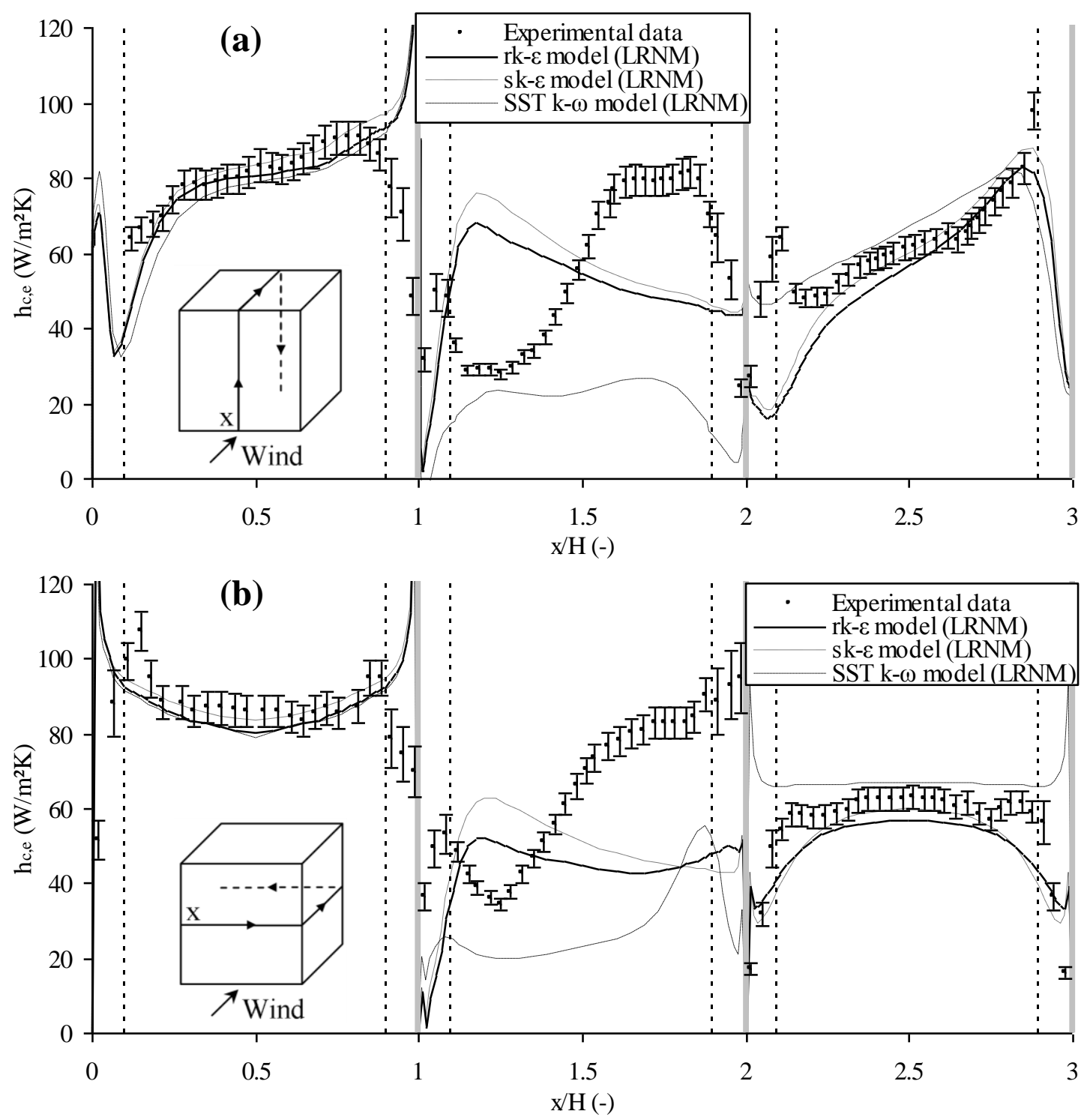

Fig. 5. CHTC distribution on the surfaces of the cube in a vertical (a) and horizontal (b) centreplane - comparison of different turbulence models (LRNM) with experimental data (with standard deviation) of Meinders et al. [20]. 
Defraeye T., Blocken B., Carmeliet J. (2010), CFD analysis of convective heat transfer at the surfaces of a cube immersed in a turbulent boundary layer, International Journal of Heat and Mass Transfer 53 (1-3),

297-308. http://dx.doi.org/10.1016/j.ijheatmasstransfer.2009.09.029
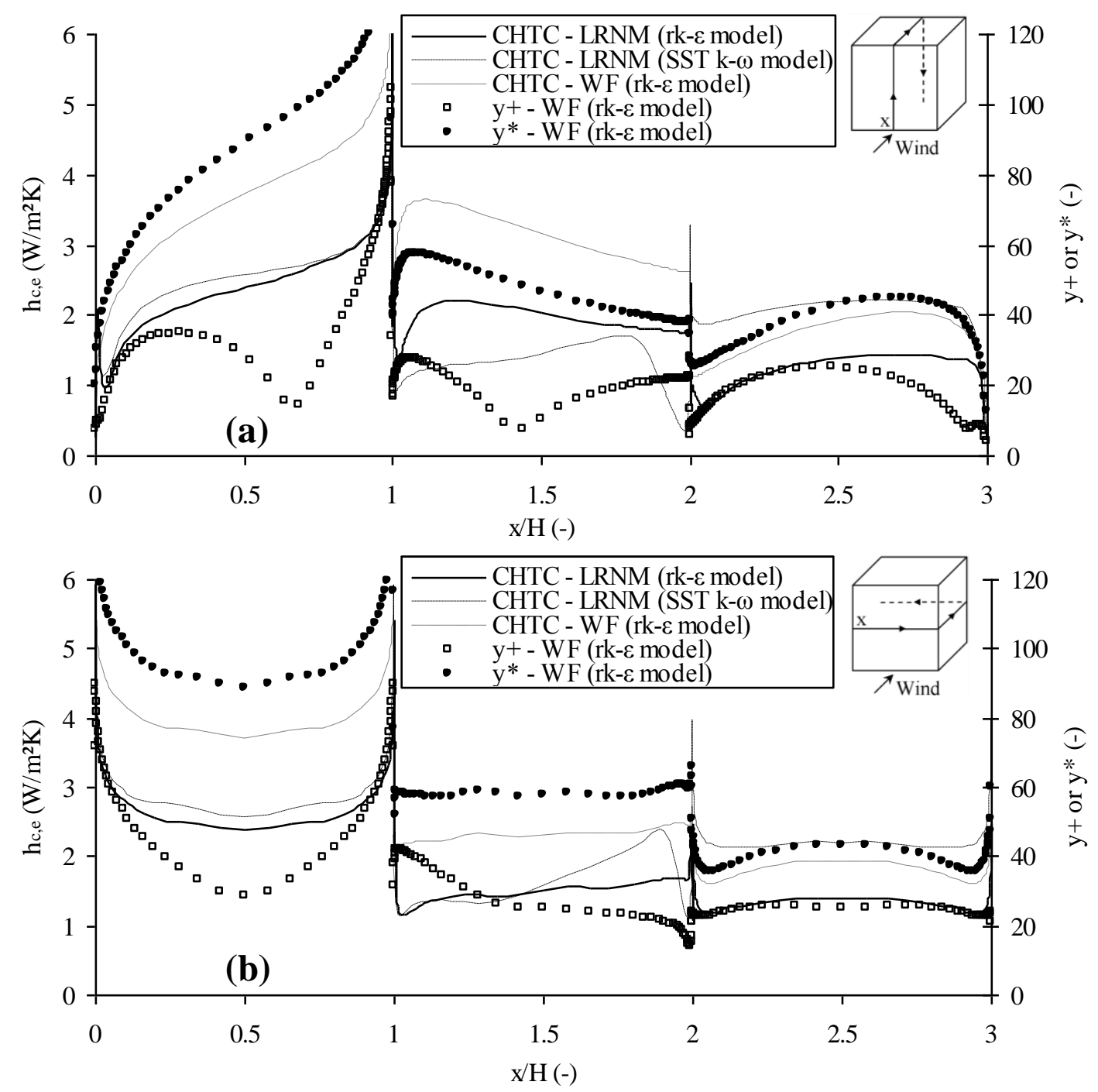

Fig. 6. CHTC distribution on the surfaces of the cube (for wall functions and LRNM) and distribution of $\mathrm{y}^{+}-\mathrm{y}^{*}$ in the wall-adjacent cell (for wall functions) in a vertical (a) and horizontal (b) centreplane. 
Defraeye T., Blocken B., Carmeliet J. (2010), CFD analysis of convective heat transfer at the surfaces of a cube immersed in a turbulent boundary layer, International Journal of Heat and Mass Transfer 53 (1-3), 297-308. http://dx.doi.org/10.1016/j.ijheatmasstransfer.2009.09.029

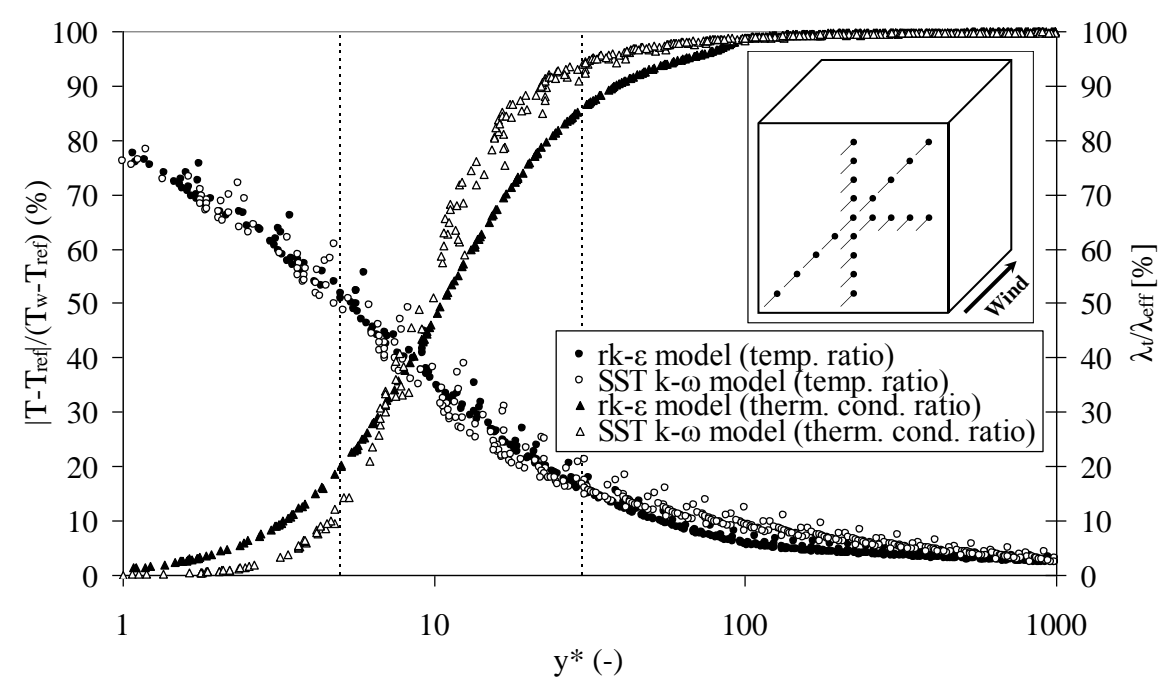

Fig. 7. Dimensionless temperature profiles $\left(100 \%\right.$ for $\left.\mathrm{y}^{*}=0\right)$ and dimensionless turbulent thermal conductivity profiles at different positions on the windward surface along lines normal to the surface, as a function of the $\mathrm{y}^{*}$ value (logarithmic scale), for LRNM (LRNM rk- $\varepsilon$ model and SST k- $\omega$ model). 
Defraeye T., Blocken B., Carmeliet J. (2010), CFD analysis of convective heat transfer at the surfaces of a cube immersed in a turbulent boundary layer, International Journal of Heat and Mass Transfer 53 (1-3), 297-308. http://dx.doi.org/10.1016/j.ijheatmasstransfer.2009.09.029

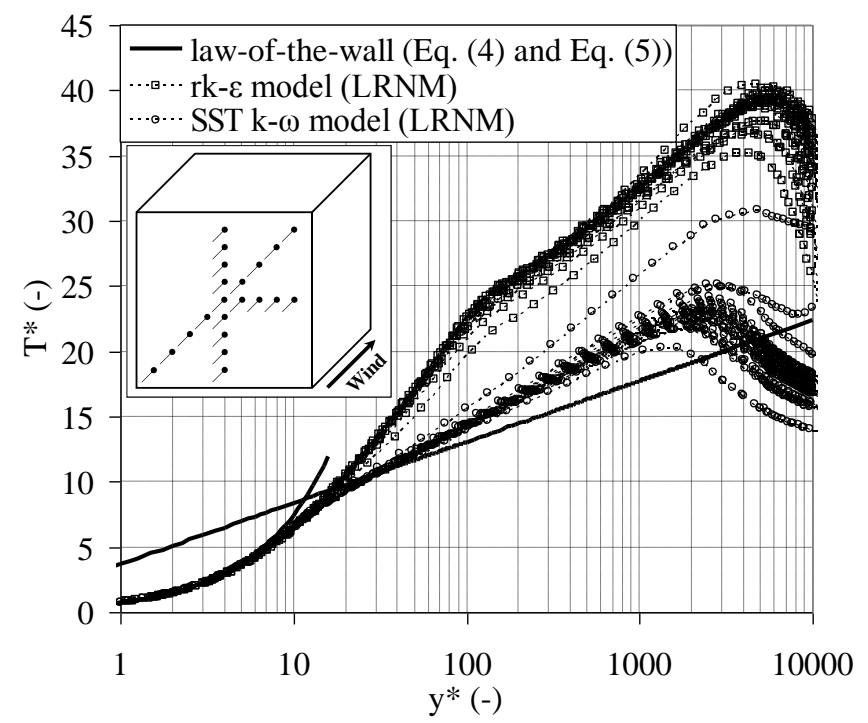

Fig. 8. Dimensionless temperature profiles at different positions on the windward surface along lines normal to the surface, as a function of the $\mathrm{y}^{*}$ value (logarithmic scale), for LRNM (LRNM rk- $\varepsilon$ model and SST k- $\omega$ model). 
Defraeye T., Blocken B., Carmeliet J. (2010), CFD analysis of convective heat transfer at the surfaces of a cube immersed in a turbulent boundary layer, International Journal of Heat and Mass Transfer 53 (1-3), 297-308. http://dx.doi.org/10.1016/j.ijheatmasstransfer.2009.09.029

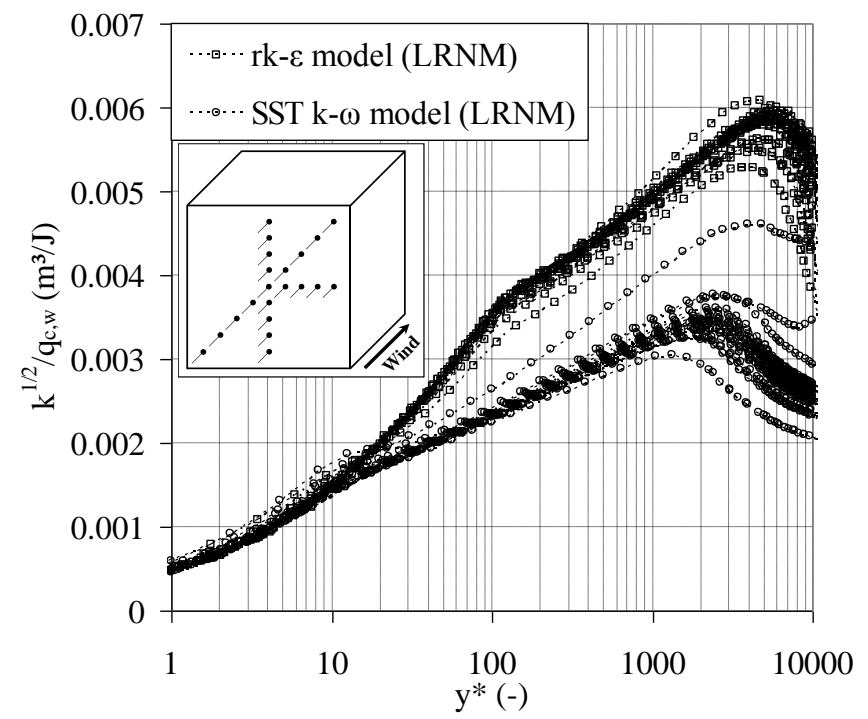

Fig. 9. Turbulent kinetic energy profiles $\left(\mathrm{k}^{1 / 2}\right)$, scaled with the heat flux at the wall, at different positions on the windward surface along lines normal to the surface, as a function of the $\mathrm{y}^{*}$ value (logarithmic scale), for LRNM (LRNM rk- $\varepsilon$ model and SST k- $\omega$ model). 
Defraeye T., Blocken B., Carmeliet J. (2010), CFD analysis of convective heat transfer at the surfaces of a cube immersed in a turbulent boundary layer, International Journal of Heat and Mass Transfer 53 (1-3), 297-308. http://dx.doi.org/10.1016/j.ijheatmasstransfer.2009.09.029

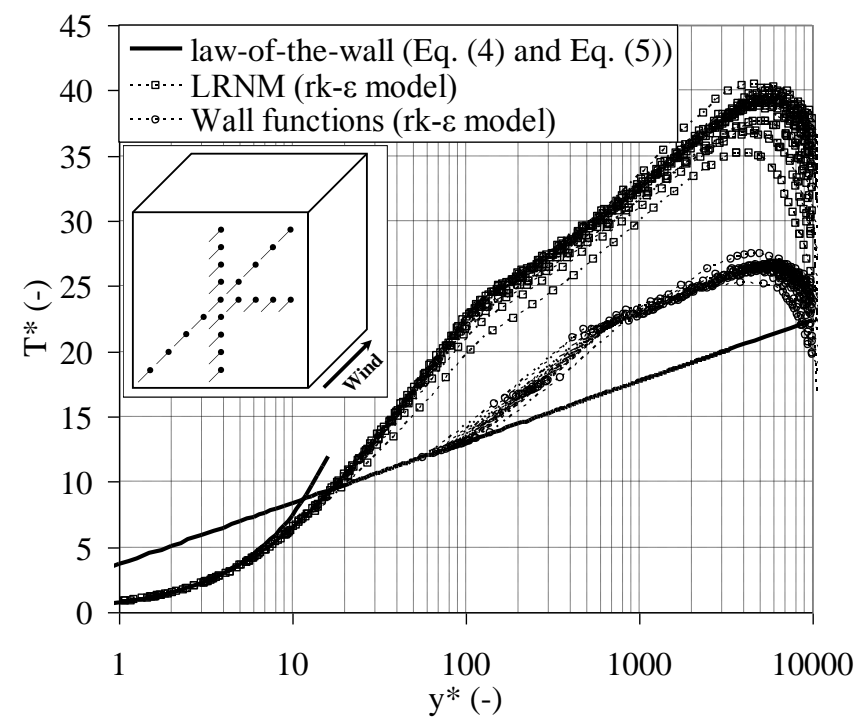

Fig. 10. Dimensionless temperature profiles at different positions on the windward surface along lines normal to the surface, as a function of the $\mathrm{y}^{*}$ value (logarithmic scale), for LRNM (LRNM rk- $\varepsilon$ model) and wall functions. 
Defraeye T., Blocken B., Carmeliet J. (2010), CFD analysis of convective heat transfer at the surfaces of a cube immersed in a turbulent boundary layer, International Journal of Heat and Mass Transfer 53 (1-3), 297-308. http://dx.doi.org/10.1016/j.ijheatmasstransfer.2009.09.029
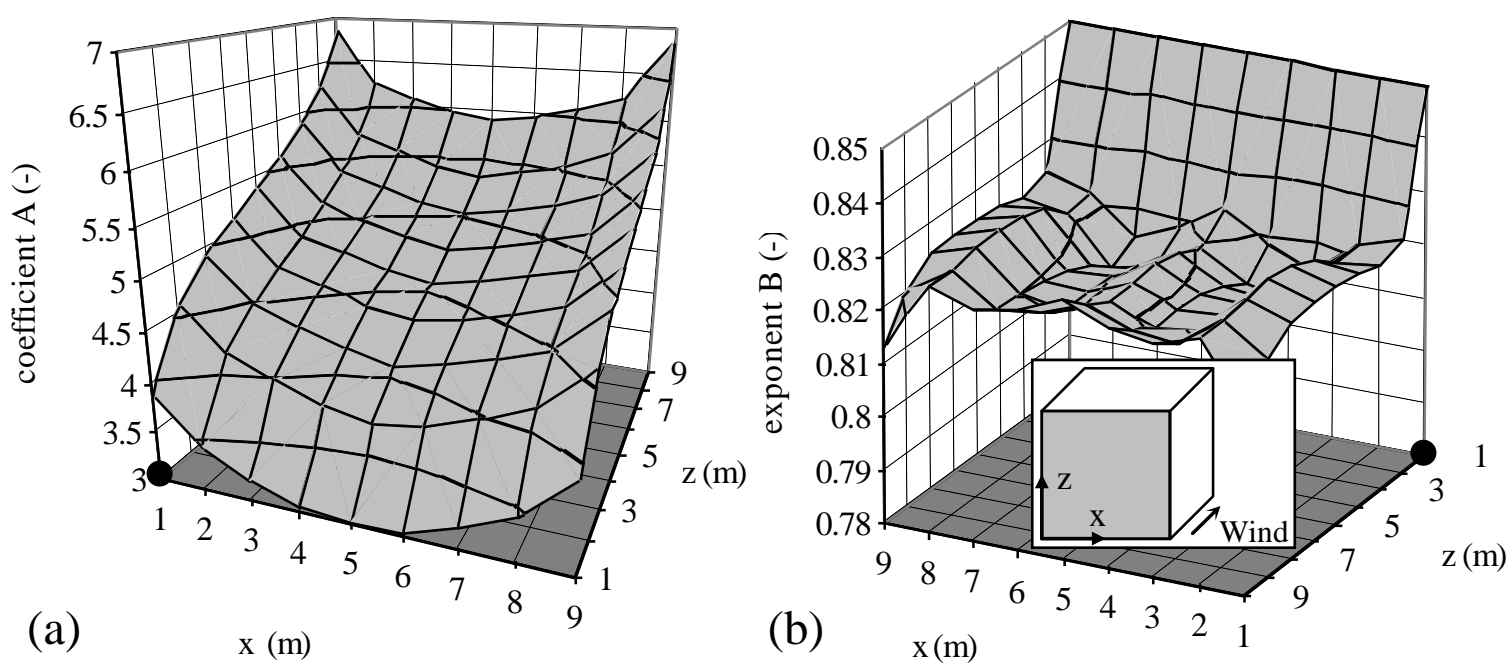

Fig. 11. CHTC-U $\mathrm{U}_{10}$ correlation (Eq. (10)): distribution of coefficient A (a) and exponent B (b) over the windward surface. 
Defraeye T., Blocken B., Carmeliet J. (2010), CFD analysis of convective heat transfer at the surfaces of a cube immersed in a turbulent boundary layer, International Journal of Heat and Mass Transfer 53 (1-3), 297-308. http://dx.doi.org/10.1016/j.ijheatmasstransfer.2009.09.029

\section{Tables}

Table 1. Properties of air and epoxy used in the simulations.

\begin{tabular}{lll}
\hline & Air & Epoxy \\
\hline Density $\left(\mathrm{kg} / \mathrm{m}^{3}\right)$ & 1.225 & 1191 \\
\hline Dynamic viscosity $(\mathrm{kg} / \mathrm{ms})$ & $1.7894 \times 10^{-5}$ & - \\
\hline Thermal conductivity $(\mathrm{W} / \mathrm{mK})$ & 0.0242 & 0.237 \\
\hline Specific heat capacity $(\mathrm{J} / \mathrm{kgK})$ & 1006.43 & 1650 \\
\hline
\end{tabular}

